\title{
AVIAÇÃO COMERCIAL REGIONAL NO ESTADO DO RIO DE JANEIRO: PERSPECTIVAS ANTE AO REGIC 2018
}

\author{
REGIONAL COMMERCIAL AVIATION IN THE STATE OF RIO DE JANEIRO: PROSPECTS REGARDING REGIC 2018
}

\section{RESUMO}

O estado do Rio de Janeiro, apesar de possuir pequena área territorial em relação às demais unidades federativas brasileiras, apresenta dificuldades de integração socioespacial, mobilidade deficitária e uma forte polarização socioeconômica na Região Metropolitana de sua capital. Entre uma série de fatores que influenciaram esse quadro, historicamente, há desde a evolução de sua divisão políticoadministrativa, à escolha pela política de mobilidade rodoviarista e até a sua topografia peculiar. A presença ou ausência de rotas aeroviárias no estado, bem sendo hoje o principal fluxo de transporte do mundo globalizado, são tanto causa como consequência do desenvolvimento socioespacial desigual e combinado. Além disso, o estudo analítico da aviação comercial regional se torna, neste momento, tanto um campo de diagnóstico quanto de ação para políticas públicas, especificamente para o nosso estado. Neste artigo, realizamos uma pesquisa qualitativa e exploratória sobre o quadro de desenvolvimento da aviação comercial regional no estado do Rio de Janeiro e utilizamos, para isso, um levantamento bibliográfico, consulta a fontes documentais como leis federais e estaduais, notícias de jornais e revistas especializadas, além de dados oriundos das pesquisas Arranjos Populacionais e Concentrações Urbanas do Brasil e Regiões de Influência das Cidades (REGIC) do IBGE.

Palavras-chave: Aviação comercial. Aeródromos. Região. Rede urbana. Estado do Rio de Janeiro.

\section{ABSTRACT}

The state of Rio de Janeiro, despite of having a small territorial area in relation to the other Brazilian federative units, presents socio-spatial integration difficulties, deficient mobility and a strong socio-economic polarization in the Metropolitan Region of its capital. Among a series of factors that have influenced this picture, historically, there are since the evolution of its political-administrative division, to the choice for the road mobility policy and even its peculiar topography. The presence or absence of air routes in the state, that is today the main transport flow in the globalized world, are both cause and consequence of an uneven and combined socio-spatial development. In addition, the analytical study of regional commercial aviation is, at the moment, both a diagnosis and action field for public policies, specifically for our state. In this article, we conducted a qualitative and exploratory research on the regional commercial aviation development situation in the state of Rio de Janeiro and, therefore, we made a bibliographic research, consulted documentary sources such as state and federal laws, articles from newspapers and specialized magazines, and the data from the Population Arrangements and Urban Concentrations of Brazil research and the Cities Influence Regions (REGIC) research, both from IBGE.

Keywords: Commercial aviation. Airports. Region. Urban network. State of Rio de Janeiro.

\author{
Dlisses da Silva Fernandes ${ }^{a}$ \\ D Gabriel Teixeira Barros ${ }^{\text {a, }}$ b \\ a Universidade do Estado do Rio de \\ Janeiro (UERJ), Rio de Janeiro, RJ, Brasil

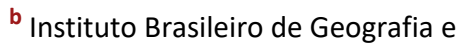 \\ Estatística (IBGE), Rio de Janeiro, RJ, \\ Brasil
}

DOI: $10.12957 /$ geouerj.2020.58673

Correpondência: udsfernandes@gmail.com

Recebido em: 7 mai. 2020

Aceito em: 13 dez.2020 


\section{INTRODUÇÃO}

A história da aviação fluminense confunde-se com a própria história da aviação comercial brasileira, haja vista ter sido a cidade do Rio de Janeiro o antigo Distrito Federal do país, capital da República, e centro polarizador e difusor de atividades de toda monta por muitas décadas - a explanação inicial, portanto, reside na distinção da toponímia Rio de Janeiro ao longo da história, bem como os efeitos que o arranjo territorial guardado pelo hoje estado do Rio de Janeiro logrou sobre a rede urbana fluminense e sobre a sua respectiva malha aérea. De início, deve-se observar a dimensão territorial que abarque um atual estado do Rio de Janeiro considerando os diferentes estatutos jurídicos experimentados pelo mesmo, como visto no Quadro 1 abaixo, organizado a partir de Miguel Angelo Ribeiro (2002):

Quadro 1. Diferentes Estatutos Jurídicos do Território Fluminense. Fonte: Os autores, adaptado de Ribeiro (2002).

\begin{tabular}{|c|l|}
\hline Ano & \multicolumn{1}{|c|}{ Evento } \\
\hline 1543 & Início das Capitanias Hereditárias \\
\hline 1565 & Fundação da cidade do Rio de Janeiro, no morro Cara de Cão \\
\hline 1567 & Transferência do sítio urbano para o morro do Castelo \\
\hline 1763 & Transferência da capital da colônia de Salvador para o Rio de Janeiro \\
\hline 1808 & Chegada da Família Real \\
\hline $1815-1822$ & Criação da Província do Rio de Janeiro \\
\hline 1834 & Criação do município neutro, separação da cidade do Rio de Janeiro da província fluminense \\
\hline 1835 & Niterói é elevada à condição de capital da província fluminense \\
\hline $1889-1891$ & $\begin{array}{l}\text { Proclamação da República e Constituição Republicana. O município neutro transforma-se em } \\
\text { Distrito Federal e a província em unidade da federação (estado) }\end{array}$ \\
\hline 1960 & $\begin{array}{l}\text { Perda da capitalidade da cidade com transferência do Distrito Federal para Brasília. Criação do } \\
\text { estado da Guanabara, com capital no Rio de Janeiro (cidade-estado) }\end{array}$ \\
\hline 1975 & $\begin{array}{l}\text { Fusão. Criação do novo estado do Rio de Janeiro, a partir dos estados da Guanabara e do antigo } \\
\text { estado do Rio de Janeiro, cuja capital é a cidade do Rio de Janeiro. Nesse momento, Niterói perde } \\
\text { a sua capitalidade. }\end{array}$ \\
\hline
\end{tabular}

A partir do quadro sucinto se pode averiguar que a cidade do Rio de Janeiro e o restante do atual território fluminense guardaram dimensões e estatutos próprios por longo tempo. O esclarecimento devido se dá em função das próprias particularidades delimitadas expressas nestes mesmos estatutos jurídicos, pois a dimensão atual do território fluminense não fora a mesma de tempos de outrora. Deste modo, aponta-se metodologicamente para um recorte que guarde as dimensões atuais e a conformação jurídico-administrativa presente desde 1975.

Tal cuidado metodológico deriva da preocupação com o entendimento sobre a dinâmica espacial carioca dissociada da dinâmica territorial fluminense desde longa data (FERREIRA, 1989). Em largos passos, o processo de urbanização observado junto à Região Metropolitana do Rio de Janeiro levou a uma concentração populacional e, em decorrência, a uma também centralização das atividades de caráter urbano-industrial, notadamente a indústria, o comércio, os serviços (MARAFON et al., 2011) e dos serviços terciários de alta complexidade. De fato, há uma expressiva concentração populacional em torno da metrópole principal, a cidade do Rio de Janeiro, e um 
esvaziamento relativo do interior fluminense. Afora a grande concentração metropolitana, a rede urbana se torna fluida em grande parte do território, mas sempre guardando a presença inequívoca de alguns aglomerados populacionais urbanos, com razões específicas ou singulares, em pontos diferentes do estado do Rio de Janeiro (RIBEIRO et O’NEILL, 2015), como em Campos dos Goytacazes e Volta Redonda-Barra Mansa.

A extensão diminuta do território fluminense e sua disposição NE-SO encaixada entre as baixadas litorâneas e as escarpas do Planalto Atlântico (ROSS, 1985) permite um deslocamento relativamente fácil através de vias terrestres, quando feito na direção diagonal. Nesse sentido, para além dos peabiru, caminhos indígenas pré-coloniais usados pelos expropriadores portugueses, seguiu-se, já no período monárquico, a implantação de uma malha ferroviária, algo que transfigurou a rede urbana originalmente colonial e perseverante até meados do Século XIX (MARAFON et al., 2011).

Obviamente, não se pode pressupor a existência de uma rede geográfica calcada tão somente em modais de transporte. Como atesta Ribeiro (2000, p. 99), "no domínio da produção capitalista crescente e diversificada destacam-se os diversos tipos de redes, que assumem diversas formas de manifestações", sendo "cada vez mais relevantes para a análise do mundo atual”. Como diz Corrêa (2012, p. 211) - considerando Saskia Sassen (2001 [1991]) -, "as múltiplas redes geográficas entrelaçadas recobrem toda a superfície terrestre" e "algumas são nitidamente de âmbito global, com centros e interações em dezenas de países, tendo Londres, Nova York e Tóquio como seus epicentros". Mas, ainda em acordo com Corrêa (2012, p. 211), "existem redes, contudo, que ao menos no plano formal, não apresentam uma dimensão global, situando-se em escala nacional ou regional".

Deste modo, deve-se reiterar: não seria apenas a difusão das redes e dos meios de transportes a única razão para o estabelecimento de uma rede geográfica configurada na existência e interconexão dos municípios fluminenses. Por outro lado, o avanço das múltiplas atividades produtivas, o entrelaçamento entre gestão e o avanço técnicoinformacional pode fazer variar a intensidade dos fluxos e a qualidade das redes (RIBEIRO, 2000). Há, de certo, municípios fluminenses, com destaque para a própria capital, interconectados em redes de expressão mundial, entretanto, a maioria dos municípios fluminenses estão interconectados em redes de caráter nacional ou regional, se muito.

Nesse sentido, o apanhado sobre os estatutos jurídicos que fundamentaram a existência do estado do Rio de Janeiro na sua configuração territorial atual, as singularidades do espaço fluminense e a explicitação da interação de uma rede de localidades tendo por base o avanço dos meios e das redes de transportes permitem entender a multiplicidade qualitativa e quantitativa dos fluxos inerentes a uma região de influência definida a partir do Rio de Janeiro. Por outro lado, como visto a partir do REGIC ${ }^{1}$ (IBGE, 2020b, 2008, 2000), há uma rede de cidades interioranas

\footnotetext{
${ }^{1}$ Optamos por usar a designação "o REGIC", conforme a apresentação do REGIC 1993 (IBGE, 2000, p. 5, grifo nosso), porém entendemos que também é possível usar o termo "a REGIC", conforme a apresentação do REGIC 2018 (IBGE, $2020 b$ ).
} 
ou arranjos populacionais (IBGE, 2016) a comandar interações e fluxos, condicionando redes geográficas, mesmo em escala sub-regional.

Quando olhamos para a aviação aérea geral é possível enxergar esta multiplicidade escalar que entroniza a rede de localidades inerente ao território do Estado do Rio de Janeiro. O que é advogado e trabalhado a seguir aponta para três situações gerais:

a) A interconectividade aérea do Rio de Janeiro está a par com esta multiplicidade escalar demonstrada anteriormente e fundamentada em autores como Ribeiro (2000) e Corrêa (2012);

b) A aviação comercial brasileira, representada por seus conglomerados aéreos, não se alinha, necessariamente, às necessidades de articulação interna do espaço fluminense com base no que pode ser definido pelo estudo das áreas de influência no estado do Rio de Janeiro.

c) Ao contrário do que pode definir outras redes técnicas, como o modal rodoviário, há uma pequena interação aérea do espaço territorial fluminense.

Figura 1. Regiões de Governo do Estado do Rio de Janeiro e aeródromos civis em 2020. Fonte: Os autores, 2020.

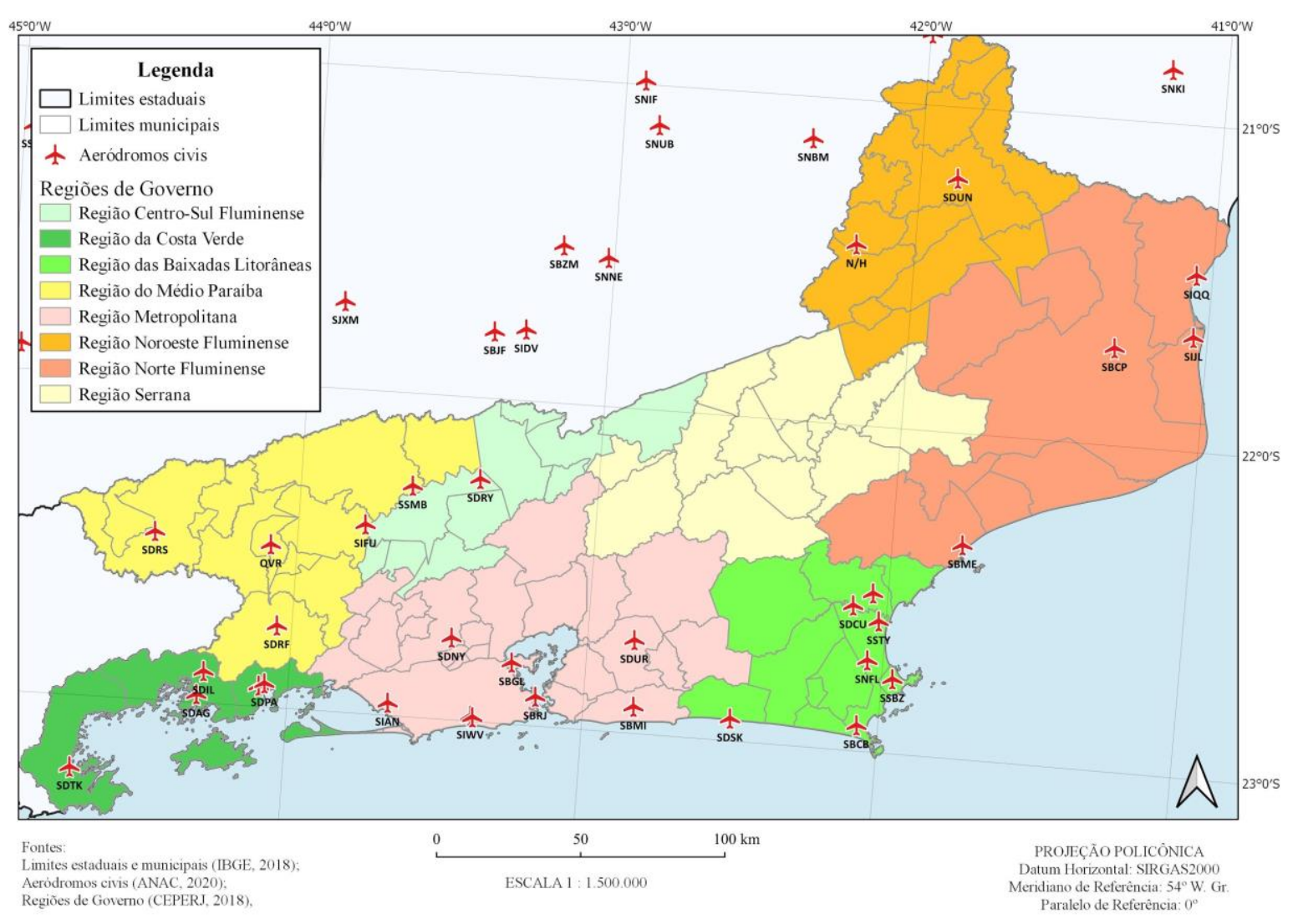

A própria proposta de regionalização do estado do Rio de Janeiro organizada a partir da antiga Fundação Centro de Informações e Dados do Rio de Janeiro (CIDE) - e atual Centro Estadual de Estatísticas, Pesquisas e Formação de Servidores Públicos do Rio de Janeiro (CEPERJ) - aponta, mesmo que indiretamente, para a predominância de 
concentrações urbanas ou arranjos populacionais (IBGE, 2016) - nas oito regiões de governo destacadas. Por outro lado, uma consulta ao Programa de Desenvolvimento da Aviação Regional - PDAR (BRASIL, 2015), coordenado atualmente pela Secretaria Nacional de Aviação Civil do Ministério da Infraestrutura no âmbito do governo federal, bem como ao Plano Aeroviário do Estado do Rio de Janeiro - PAER 2017 (RIO DE JANEIRO, 2017), nos permite aferir que grande parte dessas concentrações estão correlacionadas à existência de aeroportos-aeródromos ${ }^{2}$ já instalados ou com previsão de instalação, com notável exceção da Região Serrana - vide a Figura 1.

Portanto, objetivamos verificar a atual condição dos deslocamentos aéreos no estado do Rio de Janeiro e, de modo indireto, entender como a presença dos fixos correlacionados à aviação comercial regional - os aeródromos - é dimensionada pelos arranjos populacionais e concentrações urbanas de maior destaque presentes no território fluminense. Nesse sentido, para além do entendimento do que preconizam com respeito à aviação de caráter regional o PDAR, instituído pela lei federal 13.097, de 19 de janeiro de 2015 (BRASIL, 2015) - ainda não regulamentado pelo Poder Executivo - e o PAERJ 2017 - que constitui-se na atualização do plano aprovado originalmente pela Portaria do Comando Geral da Aeronáutica no 769/GC 5, de 31 de outubro de 2002 -, três publicações do Instituto Brasileiro de Geografia e Estatística - IBGE se tornam basilares: Arranjos populacionais e concentrações urbanas no Brasil (IBGE, 2016), Ligações aéreas (IBGE, 2013) e Regiões de Influência das Cidades - REGIC (IBGE, 2020b, 2008, 2000). A partir da análise dos planos, das publicações citadas e de revisão bibliográfica pertinente, podemos responder às questões e tratar dos objetivos aqui introduzidos.

\section{ENTENDENDO AS CENTRALIDADES REGIONAIS: UMA ANÁLISE A PARTIR DOS REGIC}

As redes geográficas formam uma categoria analítica muito cara às ciências em geral e à Geografia em um mundo globalitário. Utilizadas em conjunto com outras categorias geográficas ontológicas, elas podem desvendar conjuntos de relações de proximidade que a leitura topográfica tradicional esconde por trás do distanciamento físico. Na conceituação mais abstrata, aquela da linguagem matemática, uma rede é definida como "um conjunto estruturado de ligações ou de fluxos, em que os 'fios' entre os 'nós' são chamados de 'arcos' e os 'nós' são [...] também chamados nós, com tudo isso compondo uma trama integrada, é uma rede" (SOUZA, 2013, p. 167). Porém, na esfera concreta, a adjetivação do termo "redes" como geográficas traz consigo uma dimensão social, que é melhor descrita pela definição de Corrêa (2018, p. 50):

trata-se do conjunto de localizações humanas articuladas entre si por meio de vias e fluxos. [...] As redes geográficas são redes sociais espacializadas. São sociais em virtude de serem construções humanas, elaboradas no âmbito de relações sociais de toda ordem, envolvendo poder, cooperação e relações em outras esferas da vida.

\footnotetext{
2 Em acordo com o Código Brasileiro de Aeronáutica, um “Aeródromo é toda área destinada a pouso, decolagem e movimentação de aeronaves", bem como consideram-se "Aeroportos os aeródromos públicos, dotados de instalações e facilidades para apoio de operações de aeronaves e de embarque e desembarque de pessoas e cargas" (BRASIL, 1986, n.p.).
} 
Suas propriedades fundamentais, a conexidade e a sistematicidade (SANTOS, 2017 [1996]), são essenciais na superestrutura do atual mundo globalizado, e ainda apresentam como possibilidade a criação de condições sociais capazes de transformar a ordem hegemônica (DIAS, 2000 [1995]). Porém, da mesma forma que podem subverter essa ordem, também podem reproduzi-la e perpetuá-la, sobretudo de modo espacialmente desigual e combinado como no processo homônimo apontado por Harvey (2014). Por fim, uma forma simples e didática de se pensar em redes geográficas é aquela para a qual aponta Raffestin (1993), quando as caracteriza sob dois aspectos complementares: redes de circulação e redes de comunicação. Este par perfaz não só a mobilidade de bens materiais, mas também as redes imateriais que transportam mensagens e todo o arcabouço passível de ser transmitido por meio delas, sendo o principal o poder. $\mathrm{O}$ autor, reconhecendo a característica mutável das redes no espaço-tempo, complementa que: "ela depende dos atores que geram e controlam os pontos da rede, ou melhor, da posição relativa que cada um deles ocupa em relação aos fluxos que circulam ou que são comunicados na rede ou nas redes" (RAFFESTIN, 1993, p. 207). Essa afirmação traz à tona o caráter político que é latente nessa forma de organização espaço-temporal, e que está presente não só nas redes de infraestrutura, quando da decisão de construí-las ou não, mas também nas redes de gestão empresarial e financeira.

No REGIC, a principal teoria de base utilizada é a Teoria das Localidades Centrais, elaborada pelo geógrafo alemão Walter Christaller (1966 [1933]) com base nos pressupostos da teoria econômica locacional clássica. Essa leitura, apesar de suas limitações e da diferença espaço-temporal entre seu lócus de criação e a utilização atual, permite iluminar de forma não-exaustiva algumas questões sobre a estrutura organizacional das cidades brasileiras e assim disponibilizá-las para uma análise qualitativa mais aprofundada.

Portanto, tendo por base, inicialmente, o que apontava a classificação do REGIC 2007 (IBGE, 2008), duas das regiões se sobressaem pela presença de Capitais Regionais $C$, onde se enquadram Campos dos Goytacazes, na Região Norte Fluminense, e Volta Redonda-Barra Mansa, na Região do Médio Vale do Paraíba. Outras quatro regiões de governo apresentam Centros Sub-regionais A, que são: Nova Friburgo, na Região Serrana; Cabo Frio, na Região das Baixadas Litorâneas; a cidade de Macaé, na Região Norte Fluminense e Itaperuna, na Região Noroeste Fluminense. Os Subcentros Regionais do tipo B estão presentes na Região da Costa Verde, em Angra dos Reis, como também na Região Serrana (Teresópolis) e na Região do Médio Vale do Paraíba (Resende). Excluindo a Região Metropolitana do Rio de Janeiro (RMRJ), com a presença da Metrópole Nacional Rio de Janeiro, apenas uma das demais regiões de governo apontadas pelo CEPERJ não teria o predomínio de uma Capital Regional ou um Subcentro Regional, que é o caso da Região Centro-Sul Fluminense, cuja cidade em maior destaque, Três Rios, é classificada como Centro de Zona A - vide as Figura 2 e 3.

Comparando o REGIC 2007 com o REGIC 2018, percebemos algumas mudanças quanto à classificação hierárquica de algumas cidades fluminenses. Se antes encontrávamos duas Capitais Regionais C, Campos dos Goytacazes na Região Norte Fluminense e Volta Redonda-Barra Mansa na Região do Médio Vale do Paraíba, a elas se 
acrescem: Cabo Frio, na Região das Baixadas Litorâneas; o arranjo Macaé-Rio das Ostras, também na Região Norte Fluminense; e Petrópolis, na Região Metropolitana do Rio de Janeiro, se considerada a divisão regional do CEPERJ.

Figura 2 e 3. Rede urbana do Rio de Janeiro - REGIC 2007 (1) e 2018 (2). Fonte: Os autores, 2020.
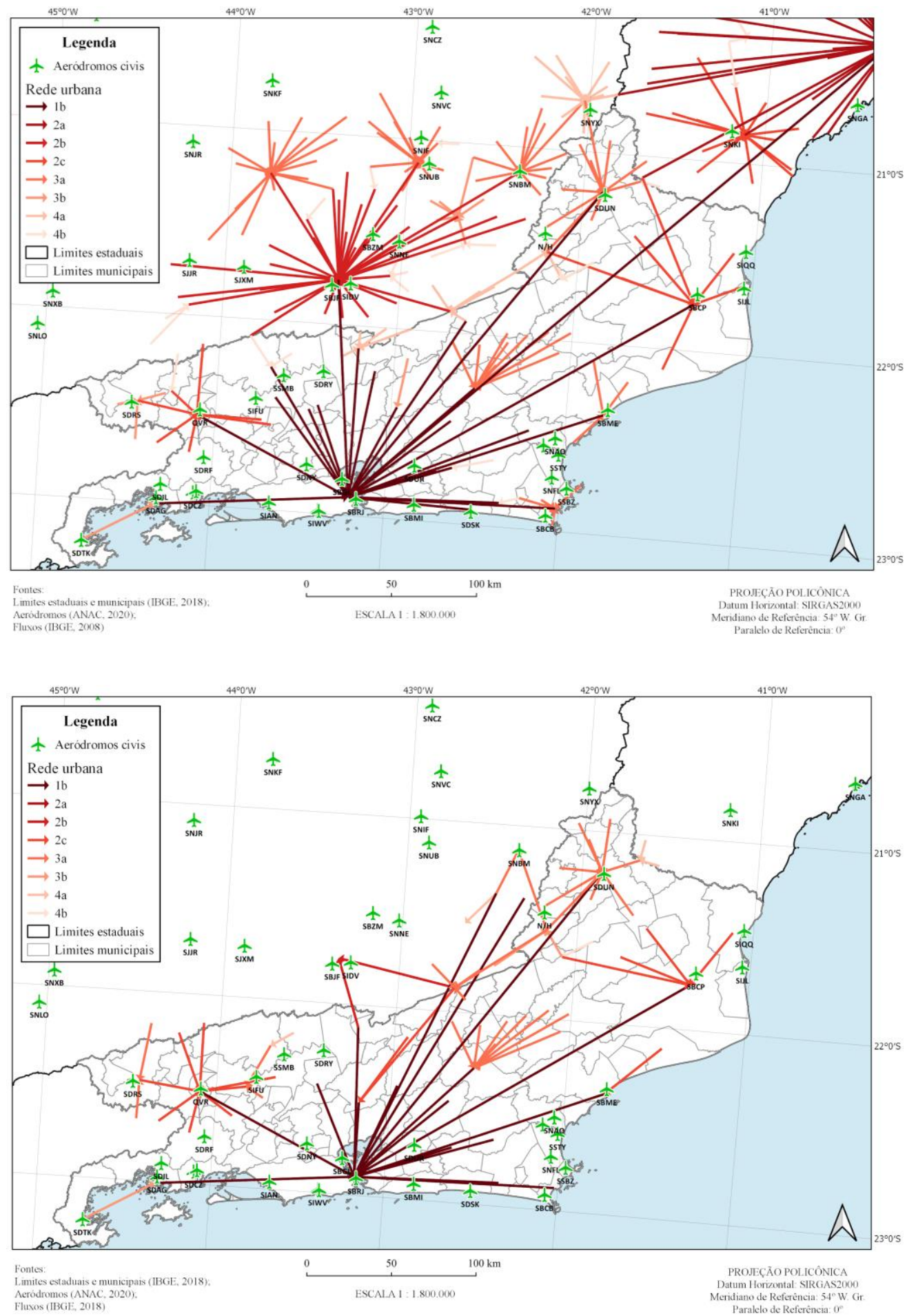

Não obstante, há de se entender que Petrópolis é considerada, no presente artigo, como pertencente à RMRJ - em acordo com a Lei Estadual Complementar no 184 de 27 de dezembro de 2018 (RIO DE JANEIRO, 2018) - e sua 
análise deve ser tomada a partir de tal perspectiva. Observa-se, também, a presença de um novo arranjo populacional relacionando Macaé e Rio das Ostras (IBGE, 2016), no que também cabe uma ressalva: o arranjo é identificado pelo REGIC 2018 (IBGE, 2020b) e mesmo que isso não dialogue com a divisão regional proposta pelo CEPERJ - Rio das Ostras está na Região das Baixadas Litorâneas e Macaé na Região Norte Fluminense - será observada desse modo em nossa análise.

Na condição de Centros Sub-regionais A permanecem Nova Friburgo, na Região Serrana, e Itaperuna, na Região Noroeste Fluminense. Nesta condição passam a constar também Resende e Barra do Piraí na Região do Médio Vale do Paraíba, bem como o arranjo populacional Além Paraíba - MG e Sapucaia - RJ (IBGE, 2016) na região Centro-Sul Fluminense. Neste último caso, a condição de extravasar divisas estaduais não será considerada imprópria para a análise de potenciais deslocamentos aéreos no território fluminense. Os Subcentros Regionais B estão presentes na Região da Costa Verde, em Angra dos Reis; na Região Serrana (Teresópolis); na Região Centro-Sul Fluminense (arranjo populacional Três Rios-Paraíba do Sul); na Região das Baixadas Litorâneas (Araruama); na Região Noroeste Fluminense (Santo Antônio de Pádua); e na Região Metropolitana do Rio de Janeiro (Rio Bonito), estando esta última em igual condição a Petrópolis.

Destaca-se, nesse ponto, que todas as Regiões de Governo fluminenses definidas pelo CEPERJ - e sem considerar a RMRJ, com a presença da Metrópole Nacional Rio de Janeiro - contam com ao menos o predomínio de uma Capital Regional ou um Subcentro Regional A ou B, o que denota uma mudança significativa na interação da rede urbana fluminense e nas áreas de influência a elas correlacionadas. A alocação dos aeródromos sobre os dois mapas destacados reforça não apenas o significado da verificação pretendida ao longo do artigo, mas também tem a função de ressaltar a busca do serviço específico, as viagens aéreas através da aviação comercial, que nem sempre são atendidas, seja nas Capitais Regionais, nos Subcentros Regionais A e B e nas demais localidades do estado.

Para além, as Figuras 4 e 5 complementam uma interpretação inicial importante para o entendimento do todo que se busca: no que pese as deficiências metodológicas do questionário específico do REGIC 2018 - 15,5\% dos municípios brasileiros não tiveram questionário aplicado -, são 4 os arranjos populacionais ou concentrações urbanas ${ }^{3}$ que apresentam maior volume de passageiros se considerarmos o hiato entre as duas pesquisas do REGIC, as de 2007 e 2018: a RMRJ, enquanto arranjo populacional, com os aeroportos Santos Dumont e do Galeão ${ }^{4}$; o arranjo populacional Macaé-Rio das Ostras, com o aeroporto de Macaé5; e as concentrações urbanas de Cabo Frio, com o Aeroporto Internacional de Cabo Frio, e de Campos dos Goytacazes, com o aeroporto de mesmo nome ${ }^{6}$.

\footnotetext{
${ }^{3}$ Cf. Nota Técnica do IBGE (2020a, n. p): "os arranjos populacionais são formados por um conjunto de municípios, fortemente integrados, que do ponto de vista funcional, constituem um único espaço urbano"; já as "concentrações urbanas são constituídas pelos arranjos populacionais ou por municípios que não fazem parte de arranjos, com mais de cem mil habitantes".

4 Tem por nome oficial Aeroporto Internacional do Rio de Janeiro/Galeão - Antonio Carlos Jobim (BRASIL, 1999), mas usamos no artigo a designação original e tradicional de Aeroporto do Galeão.

${ }^{5}$ Oficialmente denominado Aeroporto Joaquim de Azevedo Mancebo.

${ }^{6}$ Oficialmente denominado Aeroporto Bartholomeu Lysandro.
} 
Em 2018, ano de aplicação dos questionários do REGIC 2018, o Aeroporto de Macaé não estava em funcionamento ${ }^{7}$. Ele só voltou a operar voos regulares para Galeão e Santos Dumont em 2019, com a entrada em operação dos voos da VoePass (antiga Passaredo) e da Azul (TEIXEIRA, 2019). Já os aeroportos de Campos dos Goytacazes e Cabo Frio estavam em funcionamento. O Aeroporto de Itaperuna também não estava em funcionamento para a aviação regular havia muitos anos (PRONTA..., 1998) ${ }^{8}$.

Em considerando a chamada aviação geral, ao analisarmos a diferença entre os dois REGIC, foi possível perceber que alguns municípios não responderam aos questionários ou não apontaram ligação aeroportuária de ordem 2 ou 3 em 2018, e eram municípios que tinham ligações de preferência no uso do serviço aeroportuário com Campos dos Goytacazes e Macaé. Porém, isso não esconde a perda de centralidade dessas localidades capturadas pela capital fluminense. Isso fica claro, por exemplo, se olharmos para os casos de São Francisco do Itabapoana e São Fidélis, que tinham ligação de nível 1 com a cidade de Campos dos Goytacazes em 2007 e em 2018 apresentam apenas a ligação nível 1 com o Rio de Janeiro. São Fidélis apresentava ainda o aeroporto de Itaperuna como segunda opção.

Figura 4 e 5. Ordem de preferência para o uso do aeroporto - questionário REGIC 2007 (1) e 2018 (2). Fonte: Os autores, 2020.

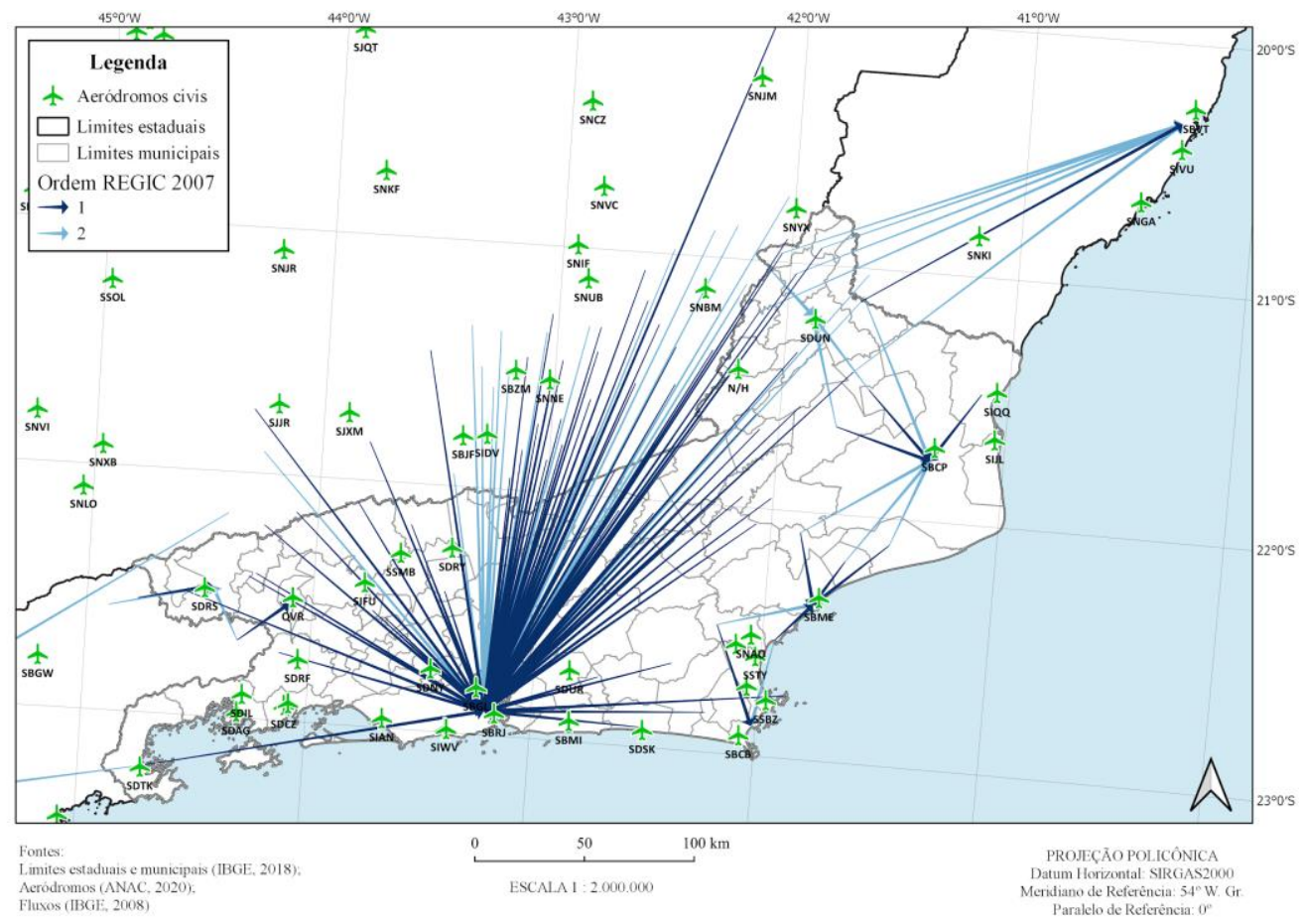

\footnotetext{
7 O aeroporto permaneceu fechado entre 2015 e 2019. De início porque a empresa aérea Azul, a única a operar em Macaé, deixou de contar com o avião ATR-42, aeronave com capacidade de operar em acordo com as pistas do aeroporto até então (ÚNICA..., 2015). Posteriormente, a INFRAERO, mantenedora do aeroporto, iniciou obras, construindo uma nova e ampliada pista, bem como um novo terminal de passageiros, sendo reinaugurado em 12 de março de 2019 (MARTINS, 2019b).

${ }^{8}$ Na seção Pronta Referência de O Guia Panrotas, n. 309, de dezembro de 1998, à p. B-225, vemos indicação de 1 voo diário da empresa aérea regional Rio-Sul, de segunda-feira a sexta-feira, entre os aeroportos Santos Dumont e de Itaperuna, com o uso de uma aeronave Cessna Caravan.
} 


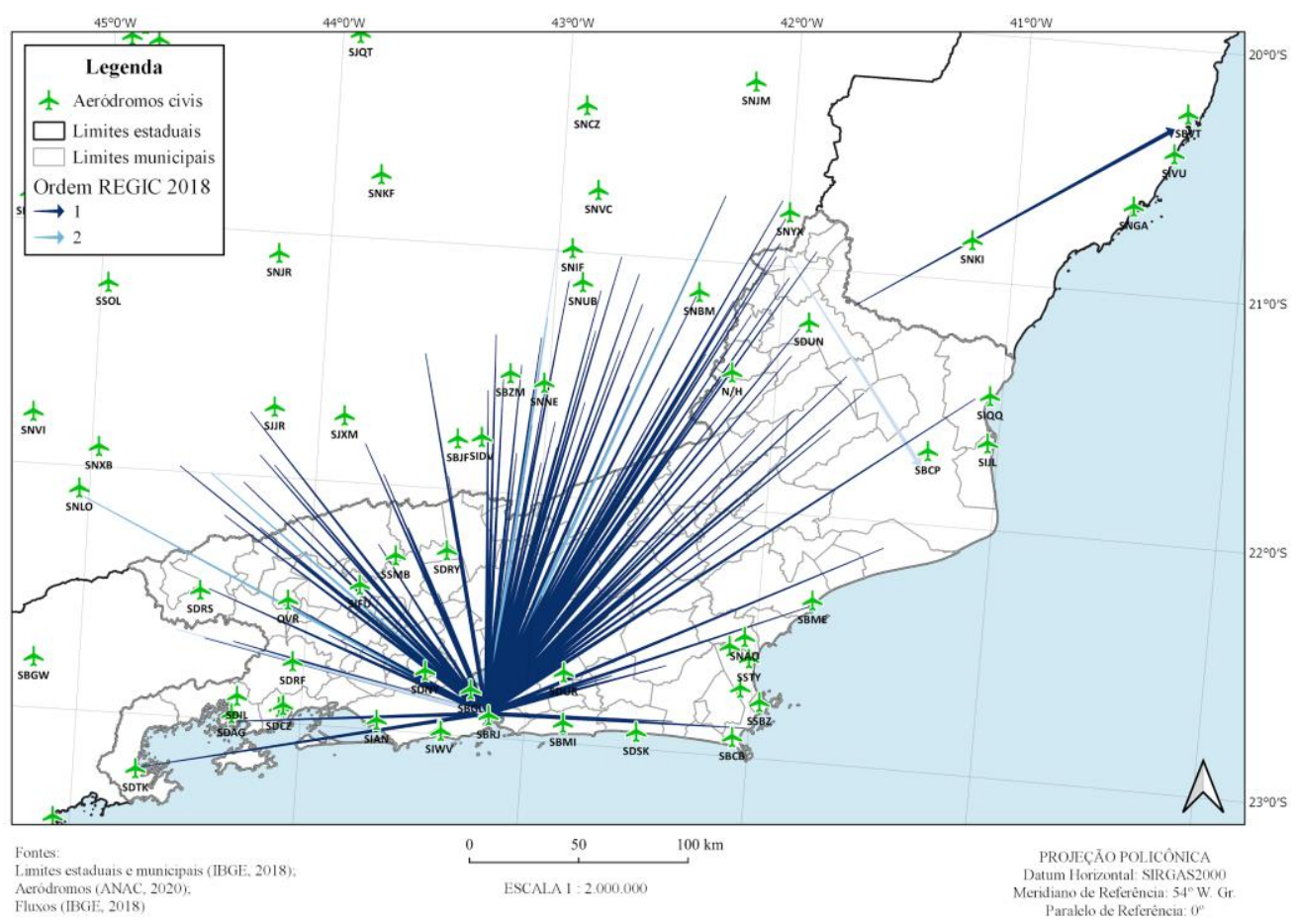

Alguns Municípios que não tiveram questionário aplicado e apresentam diferença visual significativa nos mapas em tela são: Casimiro de Abreu, que tinha em 2007 como primeira opção o aeroporto de Cabo Frio e como segunda opção o aeroporto de Macaé e a própria Rio das Ostras, que tinha como ligação de primeira ordem o Aeroporto de Macaé. No caso, a cidade de Rio das Ostras foi agregada a um arranjo populacional, logo, se no REGIC 2007 possuía dados individualizados, no REGIC 2018 aparece apenas de forma conjunta a Macaé. Conceição de Macabu e Carapebus, que apresentavam em 2007 Macaé como primeira opção e Campos como segunda opção não tiveram questionário aplicado; e Quissamã, que apresentava ligação nível 1 com Macaé e nível 2 com Campos dos Goytacazes agora apresenta apenas ligação nível 1 com o Rio de Janeiro.

No Vale do Paraíba fluminense, algumas cidades do Estado de São Paulo que se valiam dos aeroportos de Volta Redonda (RIO DE JANEIRO, 2017) e Resende (PRONTA..., 1998) ${ }^{9}$, tiveram seus fluxos redirecionados. Bananal, que os tinham, respectivamente, como primeira e segunda opção, teve seu fluxo principal capturado pelo Rio de Janeiro, enquanto Queluz, que tinha Resende como primeira opção, teve seus fluxos redirecionados para São Paulo. Arapeí apontava São José dos Campos como primeira opção e agora aponta para o Rio de Janeiro. Em 2018, São José do Barreiro passou a apontar o Rio de Janeiro como terceira opção para uso do aeroporto, enquanto Lavrinhas, que em 2007 apontava São José dos Campos como primeira opção e Resende como segunda, em 2018 não teve questionário aplicado.

\footnotetext{
${ }_{9}^{9}$ Assim como na Nota 6, na seção Pronta Referência de O Guia Panrotas, n. 309, de dezembro de 1998, à p. 218-B, vemos indicação de 1 voo diário da empresa aérea regional TAM, de segunda-feira a sexta-feira, entre os aeroportos Santos Dumont e de Resende, com o uso de uma aeronave Fokker F-50 (PRONTA..., 1998). Já o aeroporto de Volta Redonda era destinado apenas à aviação geral (RIO DE JANEIRO, 2017).
} 
De uma forma geral, foi possível perceber nessa comparação que muitos municípios que apontavam alguma localidade como segunda opção em 2007 não o fizeram mais em 2018. Notadamente, Itaperuna era apontado como segunda opção para municípios, como São Fidélis e Cardoso Moreira - este último também teve o seu fluxo principal capturado pela capital do estado. Muitos municípios do Noroeste Fluminense que apontavam para Vitória como segunda opção não o repetiram em 2018, assim como alguns do sul de Minas Gerais em relação ao Rio de Janeiro.

No REGIC 2018, apesar da perda de comparabilidade entre alguns municípios com relação ao questionário, são apresentados outros parâmetros úteis e possíveis de serem usados na pesquisa em fluxos aéreos, como a quantidade de passageiros transportados e o Índice de Atração Temático (IAT) para o tema aeroporto. Ainda em 2013, o IBGE lançou uma pesquisa específica para a investigação de ligações aéreas (IBGE, 2013), com dados referentes a 2010 e anos anteriores.

Porém, algumas outras informações de caráter econômico e sociopolítico competem à comparação entre as Figuras 4 e 5: para além dos problemas metodológicos relacionados à pesquisa do REGIC 2018, no período 2007-2018 foram mantidas as práticas de negócio na aviação comercial brasileira derivadas ainda da desregulamentação do setor a partir da década de 1990 (CASTRO et LAMY, 1993). Com isso, a quantidade de empresas extintas, as fusões entre empresas, o surgimento de novas empresas no setor, as dificuldades de manutenção e operação de aeroportos no interior do estado explicam a esmagadora predominância dos dois aeroportos metropolitanos do estado, Galeão e Santos Dumont - e cabe uma observação: obviamente que não são comparados números de voos e passageiros transportados entre os aeroportos, haja vista a grande desproporcionalidade entre os embarques e desembarques nos aeroportos da capital do estado com relação aos demais. Também importante ponto a destacar é a existência de outros aeroportos além dos já citados em localidades distintas do estado e que já foram servidos pela aviação comercial-regional ou estão diante desta perspectiva no presente momento: Itaperuna e Resende já receberam voos da aviação comercial regular no passado (PRONTA..., 1998); Angra dos Reis e Paraty se encontram preparados para receber voos da Azul Conecta a partir de dezembro de 2020 (VIEIRA, 2020). Ademais, não se pode desconsiderar a pandemia da Covid-19, esta que foi responsável, ao longo do ano de 2020, pela quase imobilização da aviação comercial em praticamente todo o planeta, e com óbvias repercussões nas escalas nacional e regional no Brasil. Finalmente, ao considerarmos as políticas públicas em distintas escalas de apoio à aviação regional, há variabilidade no maior ou menor uso dos aeroportos do interior destacados, razão da seguinte seção do artigo.

\section{O SITAR E A POSTERIOR DESREGULAMENTAÇÃO DO SETOR AÉREO NO BRASIL}

À guisa de considerações prévias sobre a articulação de uma rede de transporte aéreo no território fluminense, ressalta-se que para além do maior equipamento aeroportuário presente no Brasil até o final dos anos 1980, o Aeroporto do Galeão, inaugurado em 1952 (INAUGURADAS..., 1952), e fora a existência do Aeroporto Santos Dumont, 
inaugurado em 1936 (FAY, 2017) no Centro da cidade do Rio de Janeiro e do Aeroporto Bartholomeu Lysandro ${ }^{10}$ em Campos dos Goytacazes, nenhuma outra cidade fluminense esteve efetivamente inserida nas malhas aéreas de empresas da aviação comercial regular atuantes no Brasil. Mesmo que outras cidades tenham tido a presença deste tipo de aviação, somente as duas cidades supracitadas e respectivos aeroportos tiveram operações contínuas da aviação comercial regular nos últimos 20 anos.

Entretanto, sabemos que desde meados dos anos 1970, já sobre o pleno domínio da aviação a jato voltada aos grandes aeroportos das maiores cidades brasileiras, diferentes políticas públicas e ações privadas levaram ao surgimento de uma aviação de cunho regional (CASTRO et LAMY, 1993). Sendo assim, não se omite, que em função das demandas do Sistema Integrado de Transporte Aéreo Regional (SITAR) ${ }^{11}$ - criado pelo decreto № 76.590, de 11 de novembro de 1975 (BRASIL, 1975) - ou do Programa de Aviação Regional - PAR (BALSTER, 2016) ${ }^{12}$, distintas empresas aéreas de voos regulares atuaram em cidades como Itaperuna, Resende, Armação dos Búzios e Angra dos Reis, com existência fugaz ou intermitente. Já Macaé e Cabo Frio, pelo mesmo apelo da implantação de uma política de aviação regional, mas de um modo mais efetivo, embora sem a regularidade dos aeroportos das cidades do Rio de Janeiro e Campos dos Goytacazes, passaram a ter importância dentro da rede fluminense de aeroportos e serviços aéreos da chamada aviação comercial regular. Por fim, mesmo que o início das operações regulares nos aeroportos de Macaé e Cabo Frio tenha se dado em tempos diferentes, em ambos há uma correlação muito direta com os crescentes negócios do petróleo no litoral fluminense, o que veremos mais adiante.

O SITAR possibilitaria, quando criado, uma intervenção direta do governo federal, em comum acordo com as principais empresas aéreas existentes à época - o oligopólio Varig-Cruzeiro do Sul, Vasp e Transbrasil (PESSOA, 1989) - no sentido de planejar a aviação regional brasileira. $O$ avião idealizado pelo então governo militar para tal empreitada seria o Bandeirante [EMB-110], produzido pela fabricante estatal Empresa Brasileira de Aeronáutica (Embraer), e as empresas aéreas nacionais participariam do negócio, que seria basicamente privado, mas com apoio financeiro estatal. Sobre o início das operações das aeronaves Bandeirante [EMB-110] junto às empresas aéreas brasileiras, temos:

\footnotetext{
o primeiro voo comercial de um Bandeirante da Transbrasil ocorreu em abril de 1973. Foi um marco na história da aviação comercial brasileira: pela primeira vez, um avião projetado e fabricado no país voava regularmente numa companhia aérea brasileira. Em 4 de novembro de 1973, a VASP tornou-se a segunda empresa aérea brasileira a operar o Bandeirante: a primeira unidade de 10 encomendas entrou em serviço na data dos 40 anos de fundação da VASP (MATTOS, [200-], p. 15).
}

\footnotetext{
${ }^{10}$ Cf. Carvalho (1995), o então Aeroporto de Bonsucesso foi inaugurado em 19 de outubro de 1952, tendo seu nome posteriormente modificado para Bartholomeu Lysandro.

${ }^{11}$ Ver artigo da revista Em Discussão (INCENTIVOS..., 2010, n. p.), conforme o 1o parágrafo: “o Sistema Integrado de Transporte Aéreo Regional (SITAR), programa criado em 1975, dividiu o território nacional em cinco áreas, cada uma delas atendidas por uma única empresa que não podia ter operações nacionais. Incentivos oficiais à aviação regional incluíram adicional tarifário de $3 \%$ sobre bilhetes aéreos, que servia para subsidiar linhas aéreas deficitárias do SITAR, mas recursos pararam de ser recolhidos em 1999". ${ }^{12}$ Considerando Balster (2016, p. 55), o programa foi lançado em dezembro de 2012 pela Secretaria de Aviação Civil e "pretendia dotar o país de uma rede de 270 aeroportos regionais aptos a receberem voos regulares". Sua nomenclatura, porém, desapareceu nas recentes e sucessivas mudanças no comando do Poder Executivo que se deram no país, tendo sido posteriormente modificado e denominado com a atual nomenclatura: PDAR (BRASIL, 2015).
} 
Foram propostas cinco regiões no território brasileiro para a atuação de cinco empresas regionais a serem criadas para atender a cada uma das regiões designadas. Gianfranco Beting ([20--]) explicita a abrangência dessas regiões e a natureza das empresas aéreas criadas por mobilização do SITAR:

em 12 de novembro de 1975, o Governo Federal e as principais empresas aéreas do Brasil reuniram-se para encontrar uma solução. Nascia ali o SITAR - Sistema de Transporte Aéreo Regional. A ideia era simples: dividir o país em cinco regiões, que seriam servidas por cinco novas empresas de caráter regional. Estavam plantadas as sementes da criação de cinco novas empresas aéreas: Nordeste, RioSul, TABA, Tam e Votec. Em comum, além da missão de integrar este país-continente, todas elas tinham algo especial: a clara preferência pelo Embraer Bandeirante como aeronave principal na composição de suas frotas (BETING, [20--], n. p).

De certo, os anos de 1990 trouxeram uma desregulamentação (FERREIRA, 2017) que, senão total, foi responsável por uma forte modificação no quadro de empresas aéreas brasileiras, incluindo as de grande porte, as consideradas de aviação nacional - Varig-Cruzeiro do Sul, Vasp e Transbrasil - e as cinco regionais criadas via SITAR e aqui discriminadas. A Nordeste e a Rio-Sul acabaram sendo incorporadas à própria Varig-Cruzeiro do Sul. A Votec foi vinculada às operações da Tam passando a se chamar Brasil Regional Central (BRC), para mais tarde ser a origem oficial da Transportes Aéreos Meridionais (Tam) enquanto empresa aérea nacional, em 1996 (BARROS, 2008). A TABA extinguiu-se em 1999, após uma séria crise financeira. Entre a última década do Século XX e a primeira do Século XXI observou-se também o encerramento de operações das três gigantes da aviação constituídas nos anos de 1970, 1980 e 1990: Varig-Cruzeiro do Sul, Vasp e Transbrasil. Se Vasp e Transbrasil faliram, restou da Varig a sua marca, incorporada a uma nova empresa de voos de baixo custo surgida em 2001, a Gol Linhas Aéreas Inteligentes (FERREIRA, 2017).

Nesse mesmo ínterim surgiram muitas outras empresas aéreas no Brasil. Muitas delas estavam vinculadas à ideia internacionalmente difundida de empresas aéreas de baixo custo ou, na expressão da língua inglesa, low-cost. Várias dessas empresas constituídas utilizavam velhas aeronaves utilizadas no passado por empresas como a VarigCruzeiro do Sul. Outras, de cunho regional, passaram a utilizar aviões turboélices no atendimento de passageiros, embora não mais necessariamente fossem essas aeronaves os agora velhos Bandeirantes [EMB-110 $]^{13}$. A Embraer, que passou a ser uma empresa privada, já fabricava turboélices de melhor qualificação, como o Brasília [EMB-120], e aprimorava-se na construção de jatos regionais, como o ERJ-145, o EMB-175, o EMB-190 e o EMB-195 (GARGIULO, 2008).

Das muitas empresas surgidas e desaparecidas entre os anos de 1990 e 2010 podemos citar: Flex Linhas Aéreas, Webjet, Fly Linhas Aéreas, BRA Transportes Aéreos, Pantanal Linhas Aéreas, META, Ocean Air, TRIP, Avianca etc. Em acordo com a Agência Nacional de Aviação Civil (ANAC, 2020) existem hoje 12 empresas aéreas de transporte regular - transporte de passageiros e/ou cargas - autorizadas a atuar em território brasileiro e, dessas, destacamos as que

\footnotetext{
${ }^{13}$ Ao longo do período de vigência do SITAR (1975), novas aeronaves foram inseridas nas atividades das cinco empresas pioneiras, como um novo avião da Embraer, o Brasília [EMB-120], e as aeronaves holandesas da fábrica Fokker, modelos 27 e 50, entre outras (PESSOA, 1989).
} 
efetivamente atendem ao território fluminense no transporte de passageiros: Azul, Gol, Tam (atual Latam), Passaredo (atual VoePass), e Two-Flex (atual Azul Conecta). As quatro primeiras elencadas têm abrangência nacional - a última foi absorvida pela Azul no ano de 2020 (VIANA, 2020) - e também respondem pela maior parte dos passageiros transportados em território nacional na atualidade, embora todas elas tenham relevância no que hoje ainda pode ser chamado de transporte aéreo regional no país. Em verdade, com exceção da Latam, todas as demais empresas, como dito, vieram no rastro da forte transformação do setor aéreo brasileiro promovida por governos de cunho neoliberal advindos a partir da década de 1990 (FERREIRA, 2017).

O rearranjo da atividade de transporte aéreo, de fato, experimentou em escala global uma forte transformação, cujos reflexos foram sentidos no Brasil. A maior desregulamentação da atividade, a menor interferência dos estados nacionais na gestão deste negócio realinhou o mercado, fez desaparecer empresas de renome internacional e fez surgir novos gigantes do setor. Mudou a geopolítica internacional dos negócios de aviação, bem como mudou também dentro do território brasileiro. A eficiência do setor de transporte aéreo no quesito rapidez, aliado ao da segurança, faz da atividade algo cada vez mais fundamental em diferentes escalas de negócios (VIEIRA, 2012).

E é nesta configuração que se encaixa a proposta de maior interiorização da aviação comercial no país. Se já não existe mais um SITAR, com forte interferência estatal, há um PDAR - Programa de Desenvolvimento da Aviação Regional (BRASIL, 2015) ${ }^{14}$, configurado a partir do governo federal considerando a introdução da infraestrutura básica necessária à atuação das empresas aéreas regulares franqueadas a atender a demanda por serviços aéreos de transporte de passageiros e cargas no Brasil. Por outro lado, na escala fluminense, pode-se destacar a existência de um PAERJ 2017, que tem por meta atender a uma ampliação da capacidade de rede de transporte aéreo no estado do Rio de Janeiro em interface com os pressupostos do PDAR definido pelo poder executivo federal. Nesse ponto, há a necessidade de se entender os pressupostos que fazem valer a aplicação do programa federal e a sua interação com o plano estadual, mesmo sabedores de que tais políticas públicas se encontram cristalizadas quanto à possibilidade de sua execução. Não se trata de detalhe, pelo contrário, mas o entendimento da atual dinâmica do serviço de transporte aéreo em território fluminense depende da prévia compreensão desses pressupostos basilares.

\section{PLANEJAMENTO DO TRANSPORTE AÉREO REGIONAL NO BRASIL E NO ESTADO DO RIO DE JANEIRO}

Se o resgate histórico nos permitiu rever o SITAR e a estratégia do poder executivo federal à época da Ditadura Militar no Brasil, em tempos mais recentes podemos observar uma retomada por parte deste mesmo poder no sentido de dimensionar políticas públicas voltadas para o setor (BRASIL, 2015). Sabemos que em 2002, 9 empresas aéreas atuavam, em todo o território nacional, na chamada aviação regional: ABAETÉ Linhas Aéreas, Mesquita

\footnotetext{
${ }^{14} \mathrm{Cf}$. Capítulo VIII: da legislação relativa aos transportes, seção I: da legislação relativa ao transporte aéreo.
} 
Transportes Aéreos (META), PANTANAL Linhas Aéreas, PENA Transportes Aéreos (PENTA), PUMA AIR, RICO Linhas Aéreas, TAVAJ Transportes Aéreos, TOTAL Linhas Aéreas, Transporte Regional do Interior Paulista (TRIP) (GOMES et al., 2002) $)^{15}$. Hoje, já incluído o cenário de incertezas gerado pela pandemia da Covid-19, vemos as seguintes empresas aéreas ativas com relação à atuação na aviação regional: Asta, com sede em Cuiabá; Abaeté, com sede em Salvador; Azul, com sede em Barueri, SP; Gol, com sede no Rio de Janeiro; Map, sediada em Manaus; VoePass (antiga Passaredo), com sede em Ribeirão Preto - SP; Latam, com sede em São Paulo; e Two Flex ${ }^{16}$, com sede em Jundiaí - SP (ANAC, 2020).

A comparação feita tem por razão o entendimento básico de que o processo de desregulamentação da aviação iniciado na década de 1990 (FERREIRA, 2017) permaneceu em curso e leva a uma intensa mudança nos players do negócio da aviação comercial, ainda mais se considerarmos a de caráter regional. A proposta original do SITAR, em 1975, envolvia financiamento público ao setor privado de aviação comercial no Brasil a considerar uma estratégia de re-interiorização do acesso aéreo perdido ao longo da implantação dos grandes aviões a jato, fundamentalmente a partir dos anos 1970 (AZEVEDO et BECHEPECHE, 2019). A desregulamentação do setor aéreo influenciou a mudança em relação às empresas aéreas, mas nunca deixou de considerar, de forma explícita ou não, a subvenção pública.

O fim do SITAR, na prática, se dá com o Decreto no 99.255, de 15 de maio de 1990 (BRASIL, 1990), no governo Fernando Collor de Mello, já com o paradigma da desregulamentação do setor aéreo nacional levando à redação do mesmo. Se antes, pela lei original do SITAR, as empresas aéreas criadas eram impedidas de se converterem em empresas de âmbito nacional - como as até então existentes Varig-Cruzeiro do Sul, Transbrasil e Vasp -, com o decreto de 1990 tal proibição deixaria de existir e as empresas regionais passaram a redirecionar os seus negócios também considerando esta nova possibilidade.

A sequência de decretos e leis que sucedem em período muito próximo ao do supracitado decreto veria a desbordar para o denominado PROFAA - Programa Federal de Auxílio a Aeroportos - derivado da Lei no 8.399, de 7 de janeiro de 1992 (BRASIL, 1992). Nas palavras de Azevedo e Bechepeche (2019, p. 100), considerando informações dispostas pelo Ministério da Infraestrutura em 2017:

o PROFAA foi administrado, inicialmente, pelo Ministério da Aeronáutica (após denominado Comando da Aeronáutica, vinculado ao Ministério da Defesa), por meio do extinto Departamento de Aviação Civil (DAC) entre os anos de 1992 e 2007. Em 2008, foi transferido para a Agência Nacional de Aviação Civil (ANAC). No ano seguinte, regressou para a responsabilidade do Ministério da Defesa. Em 2011, passou a ser gerenciado pela Secretaria de Aviação Civil da Presidência da República. Hoje em dia, os fundos para o Programa são oriundos do Fundo Nacional de Aviação Civil (FNAC) e devem ser aplicados por meio de convênios contratados entre os governos estaduais e a Secretaria.

\footnotetext{
${ }^{15} \mathrm{~A}$ VoePass, atual denominação da Passaredo, não operou entre os anos de 2002 e 2004 , razão pela qual não é citada pelos autores (CONRADO, 2013).

${ }^{16}$ A Two Flex foi adquirida pela Azul em maio de 2020 e renomeada Azul Conecta (FERREIRA, $\left.2020 \mathrm{~b}\right)$.
} 
Se o SITAR regulamentou o que seria um primeiro período de existência da aviação regional brasileira, entre os anos de 1975 e 1990, com forte intervenção estatal, logo a seguir sucedeu um hiato apontado por Novaes e Souza (2019, p. 13): "nenhum evento significativo, ou com relevância suficiente para uma nova periodização, até o (re)lançamento do PROFAA, em 2012, em um novo formato de funcionamento, e que sofre relevantes alterações no ano de 2016". Entretanto, através do PROFAA, alguns aeroportos regionais foram remodelados ou construídos, a exemplo do Aeroporto de Cabo Frio - a esse respeito Gatoeiro (2007, n. p.) fez o seguinte registro:

\begin{abstract}
o Aeroporto Internacional de Cabo Frio foi construído pelo governo do estado em parceria com a Aeronáutica através do Programa Federal de Auxílio a Aeroportos (PROFAA). A inauguração aconteceu em 1998 e, logo em seguida, o estado entregou à prefeitura de Cabo Frio a administração do empreendimento.
\end{abstract}

A mesma supracitada autora, em sua matéria de 2007, apontava para a (re)inauguração do referido sítio aeroportuário, agora com a nova designação, a de Aeroporto Internacional de Cabo Frio, ainda na vigência do PROFAA. O exemplo da construção e ampliação do Aeroporto de Cabo Frio é de certo modo icônico por mostrar claramente as interseções entre políticas públicas de quaisquer grandezas e o capital privado no que diz respeito à aviação regional. O aeroporto em questão é construído na gestão do executivo federal de Fernando Henrique Cardoso, passa ao controle ao município local, que logo após faz concessão do mesmo ao capital privado (CARVALHO, 2014). Em momento posterior, ainda na vigência do PROFAA, em 2007, recebe novos recursos públicos federais para ampliação, fundamentalmente a da pista, que se torna a segunda maior do estado (LOPES, 2009). Nova ampliação é feita em 2010 (NIEMEYER, 2010), com decisão do governo do estado do Rio de Janeiro de alocar a totalidade de recursos oriundos do PROFAA em um só aeroporto, sob concessão da iniciativa privada, em detrimento de todos os outros presentes no PAERJ em vigor naquele momento.

Já o PNLT - Plano Nacional de Logística e Transporte (BRASIL, 2007) foi criado pelo governo federal na gestão Luiz Inácio Lula da Silva, em 2007, visando o planejamento público e privado, em escala nacional, das áreas de infraestrutura e logística de transportes (LUNA et al., 2011). Este plano deu origem a iniciativas de âmbito estadual, com a mesma formatação e, por outro lado, possibilitou também a existência de planos de modais específicos de transporte para diferentes escalas no território nacional. No estado do Rio de Janeiro, projetos relacionados à logística de transportes foram circunscritos neste plano nacional, a exemplo da reativação do PAERJ, originalmente constituído no ano de 2002, mas atualizado em 2014.

Como decorrência do PNLT, no âmbito federal, podemos mencionar o PAR, lançado em dezembro de 2012 - e que posteriormente daria lugar ao PDAR -, que visou discutir as necessidades específicas do setor, a melhoria aeroportuária no interior. do país e o alinhamento de políticas públicas em relação aos estados, como também em alguns municípios dotados de aeroportos. No estado do Rio de Janeiro, o PAERJ, versão $2014^{17}$, acabou por interagir

${ }^{17}$ O PAERJ foi atualizado duas vezes, sendo uma no ano de 2014 e a vigente, a versão de 2017. 
com os pressupostos do PAR e do PDAR e alicerçar possíveis transformações na infraestrutura e logística aeroportuária do estado.

Ressaltamos que os planos aeroviários estaduais têm a sua gênese articulada à Lei no 8.399, de 07 de janeiro de 1992 (BRASIL, 1992), que destinava 25,24\% dos recursos arrecadados com tarifas aeroportuárias aos investimentos em aeroportos e aeródromos de interesse regional ou estadual através do PROFAA. O PAR, lançado em 2012, em acordo com Leurquin e Avelar (2016), está atrelado aos interesses do governo federal em constituir um Fundo Nacional da Aviação Civil (FNAC) voltado à aviação, em especial a regional, para que:

\begin{abstract}
96\% da população esteja a menos de $100 \mathrm{~km}$ de distância de um aeroporto apto a receber voos regulares. Os valores desse investimento viriam do Fundo Nacional de Aviação Civil, criado pela Lei no 12.462, de 4 de agosto de 2011, alterado pela Lei $n=12.648$, de 17 de maio de 2012 e regulamentado pelo Decreto no 8.024, de 4 de junho de 2013. Em síntese, trata-se de fundo constituído por recursos decorrentes da receita de outorga recolhida pelos concessionários de aeroportos, do Adicional sobre Tarifa Aeroportuária (ATAERO), de parcela da Tarifa de Embarque Internacional (TEI) e de Recursos Próprios Financeiros (Rendimento de Aplicação Financeira). O Fundo Nacional de Aviação Civil tem como ações prioritárias a manutenção e aprimoramento da infraestrutura aeronáutica e aeroportuária pública (LEURQUIN et AVELAR, 2016, p. 205).
\end{abstract}

Já na Lei no 14.002 de 22 de maio de 2020, regula-se o uso do fundo na seguinte forma: "no desenvolvimento e no fomento do setor de aviação civil e das infraestruturas aeroportuária e aeronáutica civil"; e "no incremento do turismo" (BRASIL, 2020, n.p.). O PAERJ, fundamentalmente a partir da versão de 2014, pressupõe que a melhor integração das atividades produtivas e da circulação de bens e pessoas em território fluminense reconheça a implementação de aeródromos que venham a atender o que tanto o FNAC quanto os programas de desenvolvimento da aviação regional preconizavam, considerando, então, o limite de 100 km para acesso aos sítios aeroportuários em condições de receber voos regulares.

PAERJ: INTERAÇÕES ENTRE A REDE AEROPORTUÁRIA, AS REGIÕES DE GOVERNO E A REDE URBANA FLUMINENSE

Na Figura 6, podemos induzir uma interação com as prioridades destacadas no PAERJ 2017 e também observar o que está total ou parcialmente consolidado em relação ao mesmo nos dias de hoje, obviamente, por arbítrio metodológico, nos atendo à análise da aviação comercial regional. De consolidado, identificamos os aeroportos regionais em Campos dos Goytacazes, Macaé e Cabo Frio, que atendem negócios associados à exploração de petróleo, off shore, serviços e turismo - neste último caso, especialmente em Cabo Frio - nas regiões Norte Fluminense e das Baixadas Litorâneas. Há nesses aeroportos a presença de uma aviação comercial regular, mesmo que ainda subdimensionada, mas as razões para tanto envolvem desde situações estruturais condizentes à falta de maior dinamismo da economia fluminense como um todo até as razões conjunturais, como o plano de negócios das empresas aéreas, a execução de obras e melhorias nos aeroportos e, presentemente, a pandemia de Covid-19. 
Atualmente, mesmo com as limitações impostas pela pandemia da Covid-19, Campos dos Goytacazes e Macaé têm ligação regular diária com a cidade do Rio de Janeiro através da Azul Conecta (ex-Two Flex) com pequenos aviões Cessna para 9 passageiros (FREIRE, 2020). Cabo Frio tem empresas e destinos mais diversos em operação na alta estação turística, com ligações da Azul com São Paulo - Aeroporto de Congonhas, Belo Horizonte - Aeroporto de Confins e Rio de Janeiro - Aeroporto Santos Dumont (MENEZES, 2020). Já a Gol atenderá a mesma estação com voos a partir de São Paulo - Guarulhos (ANDRADE, 2020) - aponta-se que a pandemia de Covid-19 impediu a manutenção dos voos internacionais regulares ou voos charter oriundos, principalmente, de Buenos Aires, na Argentina, e de Santiago do Chile.

Nestas duas regiões de governo apresentadas, destacam-se, portanto, três arranjos populacionais: Campos dos Goytacazes, Macaé-Rio das Ostras e Cabo Frio. À parte o que anteriormente já fora tratado, que não necessariamente os critérios do CEPERJ para estabelecer as regiões de governo fluminenses coincidem com os critérios utilizados pelo IBGE na definição do REGIC 2018 (IBGE, 2020) ou na configuração dos arranjos populacionais (IBGE, 2016), apontamos para o alto grau de integração destes três arranjos populacionais entre si. A disposição dos aeroportos regionais de maior movimentação em território fluminense, para além dos aeroportos metropolitanos, encampa e em parte justifica a própria existência de tais arranjos populacionais definidos, assim, pelo IBGE. Além disso, há de se observar que a definição dos Arranjos Populacionais pelo IBGE, em 2015, levou em conta critérios claramente presentes, como a existência de aeroportos com certa centralidade ou a configuração dos arranjos por conta da atividade turística em si (IBGE, 2016).

Figura 6. Níveis dos Arranjos Populacionais, grau de variedade dos serviços, índice de atratividade temático para aeroportos por arranjo, segundo o REGIC 2018; e aeródromos que estão recebendo voos regulares atualmente. Fonte: os autores, 2020.

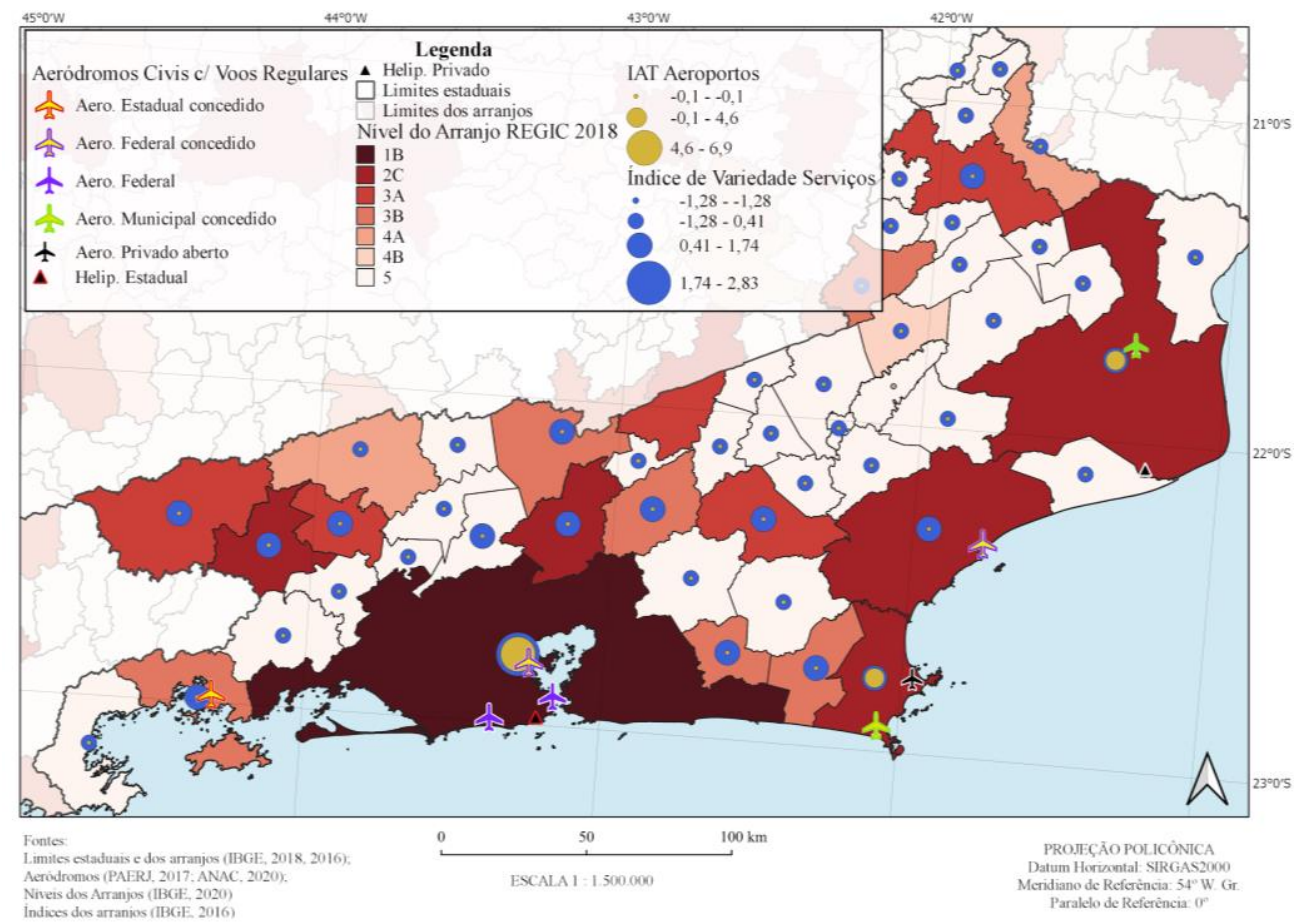


Na Região Metropolitana do Rio de Janeiro, vemos a presença de praticamente $3 / 4$ da população fluminense, a concentração das atividades produtivas e a dinâmica urbana condicionando o uso de seus três aeroportos metropolitanos principais: o Aeroporto Internacional do Galeão, um dos maiores hubs aeroportuários do país, com ligações nacionais e internacionais diversas; o Santos Dumont, com um apelo misto entre aeroporto regional e nacional; e o Aeroporto de Jacarepaguá, que atende porção distinta da Zona Oeste carioca, notadamente a Barra da Tijuca, que concentra renda e negócios do terciário de alta complexidade - é um modesto aeródromo, mas cuja localização privilegiada tem levado as empresas aéreas a conectá-lo diretamente ao Aeroporto de Congonhas, São Paulo, na chamada "Ponte Aérea da Barra" (MARTINS, 2019a, n.p.) $)^{18}$. O PAERJ 2017 ainda prevê um aeroporto no leste metropolitano, em Itaboraí, sendo este concebido dada a estimativa de maior dinamismo econômico com a instalação do COMPERJ, algo que ainda não se consolidou (RIO DE JANEIRO, 2017).

O Arranjo Populacional do Rio de Janeiro, conforme definição do IBGE (2016), só perde em termos populacionais e em Produto Interno Bruto (PIB) para o de São Paulo, sendo uma Metrópole Nacional que, em conjunto com São Paulo e Brasília, "constituem o foco dos deslocamentos para os centros urbanos do país" (CASTRO, 2020, n.p.). Assim sendo, explicitam-se as razões precípuas da concentração de sítios aeroportuários de excelência, como os Aeroportos do Galeão e Santos Dumont, para além do que a própria história política e econômica da cidade e do país justificam a importância que é devida ao arranjo populacional configurado em torno da metrópole carioca. A integração alta e média-alta desse arranjo populacional com aqueles que lhe são muito próximos, a destacar os de Petrópolis, Três Rios-Paraíba do Sul e o de Araruama, inibe o desenvolvimento da aviação regional nesses últimos - a acrescentar que a limitação territorial, proximidade geográfica e topografia são fatores que individualmente ou combinados também justificam tal inibição.

Na medida em que o PAERJ 2017 se articula a uma proposta maior, grosso modo desenvolvimentista, preconizada em terras fluminenses tanto pelos grupos políticos dominantes, como pelo próprio capital - com forte presença da Federação das Indústrias do Estado do Rio de Janeiro (FIRJAN) na elaboração de projetos -, há de se entender a sua preocupação com algumas regiões de governo do estado, com economias mais dinâmicas, e que carecem de aeródromos mais efetivos. Isto explica, por exemplo, a preocupação com os aeroportos de Paraty e Angra dos Reis, em especial este último, haja vista que além da atividade turística, associada à paisagem de praia e montanha da Costa Verde, possui atividades produtivas correlacionadas à indústria naval e de geração de energia, entre outras. Embora a conjuntura política fluminense atual esteja confusa o suficiente para se dar prognóstico a políticas públicas em curso, a decisão do governo estadual de licitar obras de ampliação do Aeroporto de Angra dos Reis e o início de operações sazonais de alta estação

\footnotetext{
${ }^{18}$ Os voos foram operados até fevereiro de 2020 através de acordo de parceria entre a empresa aérea Gol e a empresa aérea Two Flex, com aeronaves Cessna Caravan desta última. Em janeiro do mesmo ano, a Azul adquiriu a Two Flex e, em seguida, a pandemia de Covid-19 acabou por causar o fim desses voos comerciais regulares, ao menos até o final do ano de 2020 (CHENG, 2020 ).
} 
turística da Azul Conecta (antiga Two Flex) nos dois aeroportos citados fornecem indicativo claro da demanda local por ligações aéreas mais efetivas (FERREIRA, 2020a).

Dentre as chamadas Médias Concentrações Urbanas do Brasil, Angra dos Reis é um município isolado que se destaca, dentro da sua faixa de classificação, como o que apresenta o terceiro maior PIB (IBGE, 2016). Sua integração é considerada média-alta com relação ao Arranjo Populacional do Rio de Janeiro, haja vista as limitações de acesso e topografia, bem como a presença de Mangaratiba no grande arranjo populacional da metrópole carioca (IBGE, 2016). Paraty, por seu turno, além de não estar caracterizada como uma concentração urbana, herda um secular isolamento apenas quebrado após a construção da rodovia federal BR-101 e de outras obras de acesso entre os anos 1970 e 80 (MARAFON et al., 2011). Isto posto, como já visto antes, tanto o elevado PIB presente em Angra dos Reis como também as práticas turísticas associadas a esta cidade e a Paraty - e associando a relativa distância com as metrópoles São Paulo e Rio de Janeiro - justificam investimentos na ampliação do Aeroporto de Angra dos Reis ou na construção de um novo aeroporto para Paraty (RIO DE JANEIRO, 2017).

Uma outra região de governo fluminense, o Médio Vale do Paraíba, estrategicamente posicionada em relação às metrópoles Rio de Janeiro e São Paulo, tem carências de ligações aéreas de cunho regional. Se de um lado a acessibilidade pela Rodovia Presidente Dutra ou a existência de um ramal ferroviário de carga atende a demandas de circulação de bens e pessoas, o caráter executivo das viagens aéreas em função do parque industrial ali instalado, bem como dos serviços, indica a necessidade de viagens aéreas da aviação comercial regional. Para tanto, algumas limitações - inclusive previstas, mesmo que parcialmente, no PAERJ 2017 - devem ser tratadas: 1. o único aeroporto atualmente em condições de operar voos da aviação comercial regular, mesmo que limitado, é o de Resende. Este já teve operações da antiga empresa TRIP e posteriormente da Azul, mas a fusão das duas empresas e o fato da Azul posteriormente parar de operar com aviões ATR de menor porte levaram ao fim dos voos para a região (EX-SECRETÁRIO..., 2018); 2. o uso de aeronaves de maior porte cobram equipamentos e obras necessárias e, para tanto, as políticas públicas devem ser mais efetivas, tanto por parte do governo federal como também do governo estadual (EX-SECRETÁRIO..., 2018); 3. para além de cuidar da existência de um aeroporto para uso da aviação comercial regular, as políticas públicas devem prever subsídios de operação, fundamentalmente no que diz respeito à taxação do combustível (GAIER, 2019); 4. Se o PAERJ 2017 prevê a existência de um aeroporto de maior porte entre Volta Redonda e Piraí, o custo de tal obra limita a mesma aos recursos do PDAR, programa federal cuja atuação nos últimos anos esteve bastante limitada (RIO DE JANEIRO, 2017).

A Região do Médio Vale do Paraíba possui dois importantes arranjos populacionais, Resende e Volta Redonda-Barra Mansa, com alta e média-alta integração entre si. São arranjos populacionais de destaque na malha urbana fluminense e com alto valor de PIB dentro do seu grupo específico de análise (IBGE, 2016). Ao 
compararmos estes arranjos com outros de próxima ou até menor importância dentro do território fluminense percebemos a limitação da infraestrutura aeroportuária ali presente. Se, como visto, o Aeroporto de Resende possui muitas restrições para a aviação comercial regional, a proposta de criação do Aeroporto do Aço, por seu turno, é meta bastante distante (RIO DE JANEIRO, 2017).

Em respeito às demais regiões de governo do estado, temos situações bastante específicas: no Noroeste Fluminense, os Arranjos Populacionais são limitados e o destaque maior fica por conta dos municípios isolados de Itaperuna e Miracema (IBGE, 2016). O aeródromo presente em Miracema é extremamente deficiente pista curta de terra -, mas o Aeroporto de Itaperuna tem plenas condições de atender às necessidades de sua área de abrangência, carecendo de obras de recapeamento da pista e melhorias no terminal existente (RIO DE JANEIRO, 2017). Após obras com recursos do PROFAA executadas no aeroporto, em 1996, houve rota comercial implantada pela empresa Rio-Sul (Cachoeiro do Itapemirim - Itaperuna - Rio de Janeiro, Santos Dumont), mas a conjuntura do negócio da aviação levou a uma rápida desmobilização da rota (RIO DE JANEIRO, 2017). Em tempos hodiernos, a situação não é diferente: aeroporto recuperado não basta para reativar voos, mas também uma simultânea ação mais objetiva por parte do governo fluminense quanto à atração de empresas aéreas regulares para atuação local.

Na Região Centro-Sul Fluminense, onde se destaca o Arranjo Populacional Três Rios-Paraíba do Sul (IBGE, 2016), dada a sua localização geográfica e a sua menor expressão econômica e populacional dentro do estado do Rio de Janeiro, há apelo de uso do Aeroporto Regional da Zona da Mata, próximo a Juiz de Fora MG e, principalmente, dos aeroportos da Região Metropolitana do Rio de Janeiro - no PAERJ 2017 não há previsão de construção de qualquer aeroporto regional na referida região (RIO DE JANEIRO, 2017). A Região Serrana, por seu turno, tem Arranjos Populacionais limitados e baixa integração, e destacam-se municípios isolados, como Nova Friburgo e Teresópolis (IBGE, 2016). As limitações de relevo e a proximidade com os aeroportos metropolitanos determinam a direcionar aos mesmos o transporte de bens e serviços, mas, de toda forma, o PAERJ 2017 prevê, a médio prazo, a construção de um aeroporto em Cantagalo de modo a atender demandas do setor turístico e produtivo presentes na região (RIO DE JANEIRO, 2017).

Vemos que as regiões de governo fluminenses, pelas dinâmicas diversas que as caracterizam como tais ao longo da história, têm a presença de sítios aeroportuários efetivos - e voltados à aviação comercial - em pequeno número e muito concentrados. O PAERJ 2017 indica duas etapas com revisões distintas: uma mais emergencial, que finda em 2020; e outra que se estende até 2033 (RIO DE JANEIRO, 2017). Apontamos aqui para os aeroportos já existentes ou previstos com relação aos arranjos populacionais que mais se destacam em cada região de governo fluminense, isto porque tal leitura é imperativa para o entendimento das considerações finais do artigo em tela. 


\section{CONSIDERAÇÕES FINAIS}

Apesar de todas as ações projetadas e apontadas, principalmente pelo PAERJ 2017, é notória a falta de expectativas concretas de que todas ou, ao menos, parte dessas ações previstas sejam demandadas, isto para o período que se encerra em 2020 ou para o que compreende o período seguinte, até 2033. Isso se deve principalmente ao fato de que não há vinculação entre os planos apresentados e os instrumentos financeiros necessários às suas implantações. Programas federais como o antigo SITAR, o PAR, o PDAR ou o PROFAA buscam atuar como estimuladores de investimentos e sugerem algumas importantes fontes de receita vinculando os $\mathrm{PAE}^{19}$ nessas ações, porém o que se vê nas políticas mais recentes é o predomínio da desregulamentação do setor e o incentivo à política do livre-mercado. Essa opção delega às empresas aéreas a decisão de investimentos, que é prioritariamente um ato político e severamente desvinculado dos interesses públicos.

É possível perceber que os planos de investimento em infraestrutura aeroportuária do estado do Rio de Janeiro atualmente giram em torno de dois eixos: suporte off-shore, principalmente à exploração de petróleo e gás, que se refletem nos projetos dos possíveis futuros novos aeródromos de Itaboraí - no chamado Leste Metropolitano - e do Norte Fluminense, bem como na ampliação dos aeródromos costeiros de Maricá e Macaé; e o eixo do turismo, que inclui a construção do novo aeroporto de Paraty / Costa Verde e ampliação do Aeroporto de Angra dos Reis.

Observando os dados levantados e os mapas em tela, acreditamos que seja vital para uma melhor articulação do território fluminense a consideração mais efetiva das seguintes ações: 1. a instalação do Aeroporto Regional de Volta Redonda-Piraí, o pré-denominado Aeroporto do Aço, que hoje só existe como um terreno particular; 2. a revitalização do Aeroporto de Itaperuna, que é uma importante centralidade do Noroeste Fluminense: 3. a instalação de um aeroporto na Região Serrana visando atender, fundamentalmente, Nova Friburgo e Teresópolis, que se destacam na atividade turística, como também possuem oferta de grande variedade de atividades produtivas e de serviços - o PAERJ 2017 aponta para a construção de um Aeroporto Regional em Cantagalo, de modo a atender tal necessidade.

$\mathrm{Na}$ produção do artigo, foram justapostos os estudos do CEPERJ quanto às regiões de governo fluminenses, os estudos do IBGE sobre Arranjos Populacionais 2015 e o REGIC 2018, bem como o que prevê o PAERJ 2017 estadual articulado ao PDAR federal. Após tratadas as diferenças metodológicas entre as distintas propostas e estudos, partimos para a análise das correlações identificadas, sendo observadas: uma correlação muito forte entre as regiões de governo de economias mais dinâmicas com uma rede de localidades centrais

\footnotetext{
${ }^{19}$ Cf. aponta a Lei no 12.462, de 4 de agosto de 2011, citada por Leurquin e Avelar (2016, p. 205).
} 
/ arranjos populacionais melhor consolidadas; e, nestas regiões de governo, aeroportos já operantes, com a presença de voos comerciais regulares tanto nos aeroportos metropolitanos como também em Cabo Frio, Macaé e Campos dos Goytacazes. Entretanto, há uma não-correlação muito nítida, a que diz respeito ao Médio Vale do Paraíba, com uma aviação comercial regular não presente e com a ausência de um aeródromo compatível com a concentração populacional e a geração do PIB que se destacam regionalmente dentro de nosso estado. Para além, as práticas turísticas mobilizam o setor aéreo a operar em aeroportos limitados, ao mesmo tempo em que o próprio PAERJ 2017 prevê melhorias nos mesmos ou a construção de novos sítios aeroportuários mais adequados. Neste grupo, em meio à estação turística do verão 2020/2021 - e apesar dos efeitos negativos da pandemia de Covid-19 - temos as cidades de Angra dos Reis, Paraty e Armação dos Búzios, que hoje possui apenas um aeródromo privado que se dispõe a receber alguns determinados voos.

Por fim, a unidade federativa do Rio de Janeiro tem um conjunto de características que em qualquer análise similar à nossa deve ser encarado: os estatutos políticos que ao longo de sua história lhe são peculiares; o longo descolamento histórico entre a sua atual capital e o seu interior; a gigantesca concentração de população e de atividades produtivas diversas, incluídas aí as práticas turísticas, na Região Metropolitana do Rio de Janeiro; a própria disposição geográfica do território; e até mesmo pela área territorial relativamente diminuta. Tais pontos elencados condicionaram, historicamente, uma aviação altamente concentrada e centralizada nos dois principais aeroportos de sua capital: os aeroportos do Galeão e Santos Dumont. Nitidamente, o avanço da aviação comercial no Brasil como um todo, que ao longo das décadas de 1970, 1980 e 1990 concentrou e centralizou as suas operações em pouco mais de uma centena de aeroportos com a utilização de aeronaves a jato de médio e grande porte, reforçou esta condição de quase exclusividade de acesso aéreo na cidade do Rio de Janeiro para praticamente todo o estado. Se, fundamentalmente, nas duas primeiras décadas do Século XXI vemos ações públicas mais adequadas no sentido de se constituir uma aviação regional comercial mais efetiva no país como um todo, paga o Rio de Janeiro, pelas razões aqui explicitadas, com a sua presente incapacidade de promover a descentralização das operações aeroportuárias no estado e, consequentemente, deixa de colher os benefícios que a correlata desconcentração do setor possa vir a trazer para o seu maior desenvolvimento regional.

\section{REFERÊNCIAS}

ANAC - Agência Nacional de Aviação Civil. Empresas Aéreas - Consultas. Brasília, DF: ANAC, 2020. 1 base de dados. Disponível em: https://sistemas.anac.gov.br/sas/empresasaereas/view/frmEmpresas.aspx. Acesso em: 15 dez. 2020.

ANDRADE, A. Gol volta a voar para Jeri (CE), Caldas Novas (GO) e Cabo Frio (RJ). Portal Panrotas, São Paulo, 05 nov. 2020. Disponível em: https://www.panrotas.com.br/retomada-das-viagens/aviacao/2020/11/gol-volta-a-voar-para-jeri-ce-caldas-novas-go-e-cabofrio-rj_177792.html. Acesso em: 28 dez. 2020. 
AZEVEDO, M.; BECHEPECHE, A. Aviação regional na atualidade. Revista Científica Multidisciplinar Núcleo do Conhecimento, ano 4, v. 12, n. 4, p. 93-115, dez. 2019. Disponível em: https://www.nucleodoconhecimento.com.br/ciencias-aeronauticas/aviacao-regional. Acesso em: 24 dez. 2020.

BALSTER, I. O Programa de Aviação Regional e o desafio da administração dos Aeroportos Regionais. 2016. Projeto de Graduação (Engenharia Civil) - Escola Politécnica - Universidade Federal do Rio de Janeiro, Rio de Janeiro, 2016. Disponível em: http://www.monografias.poli.ufrj.br/monografias/monopoli10018631.pdf. Acesso em: 29 dez. 2020.

BARROS, A. BR Central - Brasil Central (Brasil). Portal Aviação Brasil, São Paulo, 2008. Disponível em: https://aviacaobrasil.com.br/br_central_-_brasil_central_brasil/. Acesso em: 20 dez. 2020.

BETING, G. SITAR: integrando o Brasil. Arquivo JetSite, [S. I.], [20--]. Disponível em:

https://www.aviacaocomercial.net/jetsite/nostalgia_sitar.htm\#: :text=Em\%2012\%20de\%20novembro\%20de,novas\%20empresas\%2 0de\%20car\%C3\%A1ter\%20regional. Acesso em: 14 dez. 2020.

BRASIL. Lei no 14.002, de 22 de maio de 2020. Altera as Leis $n$ os 11.371, de 28 de novembro de 2006, e 12.249, de 11 de junho de 2010, para dispor a respeito das alíquotas do imposto sobre a renda incidentes nas operações que especifica, e as Leis n os 9.825 , de 23 de agosto de 1999, 11.356, de 19 de outubro de 2006, e 12.462, de 4 de agosto de 2011; autoriza o Poder Executivo federal a instituir a Agência Brasileira de Promoção Internacional do Turismo (Embratur); extingue o Instituto Brasileiro de Turismo (Embratur); revoga a Lei no 8.181, de 28 de março de 1991; e dá outras providências. Brasília, DF: Presidência da República, 2020. Disponível em: https://www.planalto.gov.br/ccivil_03/_ato2019-2022/2020/lei/l14002.htm. Acesso em: 26 dez. 2020.

BRASIL. Lei no 13.097, de 19 de janeiro de 2015. Reduz a zero as alíquotas da Contribuição para o PIS/PASEP, da COFINS, da Contribuição para o PIS/Pasep-Importação e da Cofins-Importação incidentes sobre a receita de vendas e na importação de partes utilizadas em aerogeradores e dá outras providências. Brasília, DF: Presidência da República, 2015. Disponível em: http://www.planalto.gov.br/ccivil_03/_Ato2015-2018/2015/Lei/L13097.htm. Acesso em: 15 dez. 2020.

BRASIL (Ministério dos Transportes; Ministério da Defesa). Plano Nacional de Logística e Transportes: Relatório Executivo. Brasília, DF, abr. 2007. Disponível em: http://antigo.infraestrutura.gov.br/images/2014/11/PNLT/2011.pdf. Acesso em: 29 dez. 2020.

BRASIL. Lei no 9.778, de 5 de janeiro de 1999. Denomina “Aeroporto Internacional do Rio de Janeiro/Galeão - Antonio Carlos Jobim" ao "Aeroporto Internacional do Rio de Janeiro/Galeão". Brasília, DF: Presidência da República, 1999. Disponível em: http://www.planalto.gov.br/ccivil_03/leis/I9778.htm. Acesso em: 20 dez. 2020.

BRASIL. Lei no 8.399, de 7 de janeiro de 1992. Especifica a destinação dos recursos originados por adicional tarifário criado pela Lei n 7. 920, de 12 de dezembro de 1989, que "cria o Adicional de Tarifa Aeroportuária e dá outras providências". Brasília, DF: Presidência da República, 1992. Disponível em: https://www.planalto.gov.br/ccivil_03/leis//8399.htm. Acesso em: 24 dez. 2020.

BRASIL. Decreto no 99.255, de 15 de maio de 1990. Revoga parágrafo do Decreto no 76.590, de 11 de novembro de 1975, que dispõe sobre os Sistemas Integrados de Transporte Aéreo Regional. Brasília, DF: Presidência da República, 1990. Disponível em: https://www.planalto.gov.br/ccivil_03/decreto/1990-1994/d99255.htm. Acesso em: 24 dez. 2020.

BRASIL. Lei no 7.565, de 19 de dezembro de 1986. Dispõe sobre o Código Brasileiro de Aeronáutica. Brasília, DF: Presidência da República, 1986. Disponível em: http://www.planalto.gov.br/ccivil_03/leis/L7565compilado.htm. Acesso em: 30 dez. 2020.

BRASIL. Decreto no 76.590, de 11 de novembro de 1975. Dispõe sobre os Sistemas Integrados de Transportes Aéreo Regional e dá outras providências. Brasília, DF: Presidência da República, 1975. Disponível em:

http://www.planalto.gov.br/ccivil_03/decreto/1970-1979/D76590.htm. Acesso em: 20 dez. 2020.

CARVALHO, R. Aeroporto Internacional de Cabo Frio: Globalização, Redes e Fluxos. 2014. Dissertação (Mestrado em Planejamento Regional e Gestão de Cidades) - Programa de Pós-Graduação em Planejamento Regional e Gestão de Cidades, Universidade Candido Mendes - Campos dos Goytacazes, RJ, 2014.

CARVALHO, W. Campos depois do centenário. v. 2. Itaperuna: Damadá. 1995.

CASTRO, A. REGIC 2018 - Regiões de Influência das Cidades. Portal Rede Urbana, Campina Grande, 26 jun. 2020. Disponível em: https://aredeurbana.com/2020/06/26/regic-2018-regioes-de-influencia-das-cidades/. Acesso em: 30 dez. 2020.

CASTRO, N.; LAMY, P. Desregulamentação do Setor Transporte: o Subsetor Transporte Aéreo de Passageiros. Brasília: IPEA, 1993. (Texto para Discussão, n. 319). Disponível em: http://repositorio.ipea.gov.br/bitstream/11058/2465/1/td_0319.pdf. Acesso em: 20 dez. 2020. 
CHENG, D. Azul atrapalha plano de expansão regional da Gol com compra da Two Flex. Portal Money Times, [S. I.], 15 jan. 2020. Disponível em: https://www.moneytimes.com.br/azul-atrapalha-plano-de-expansao-regional-da-gol-com-compra-da-two-flex/. Acesso em: 28 dez. 2020.

CHRISTALLER, W. Central places in southern Germany. Englewood Cliffs: Prentice Hall, 1966 [1933].

CONRADO, A. Uma breve história da Passaredo. Portal Aviões e Música, São Paulo, 13 jun. 2013. Disponível em: http://www.avioesemusicas.com/uma-breve-historia-da-passaredo.html. Acesso em: 21 dez. 2020.

CORRÊA, R. L. Caminhos paralelos e entrecruzados. São Paulo: EdUNESP, 2018.

CORRÊA, R. L. Redes geográficas: reflexões sobre um tema persistente. Cidades, Presidente Prudente, v. 9, n. 16, p. $200-218,2012$.

DIAS, L. C. Redes: Emergência e Organização. In: CASTRO, I. E.; GOMES, P. C. C.; CORRÊA, R. L. (org.) Geografia: Conceitos e Temas. 2. ed. Rio de Janeiro: Bertrand Brasil, 2000 [1995].

EX-SECRETÁRIO destaca contribuição da Prefeitura de Resende para reabertura do Aeroporto Municipal. A Voz da Cidade, Barra Mansa, 30 jun. 2018. Disponível em: https://avozdacidade.com/wp/ex-secretario-destaca-contribuicao-da-prefeitura-de-resendepara-reabertura-do-aeroporto-municipal/. Acesso em: 30 dez. 2020.

FAY, C. M. A cidade do Rio de Janeiro e a construção do Aeroporto Santos Dumont (1933-1938). Cadernos de História, Belo Horizonte, v. 18, n. 28, jan./jul. 2017. p. 203-227. Disponível em:

http://periodicos.pucminas.br/index.php/cadernoshistoria/article/view/P.2237-8871.2017v18n28p203/11960. Acesso em: 20 dez. 2020.

FERREIRA, C. Com pista sobre o mar, Aeroporto de Angra dos Reis poderá receber voos de ATR. Portal Aeroin, [S. I.], 20 set. 2020 a. Disponível em:https://www.aeroin.net/com-pista-sobre-o-mar-aeroporto-de-angra-dos-reis-podera-receber-voos-de-atr/. Acesso em: 27 dez. 2020.

FERREIRA, C. Azul conclui amanhã a compra da Two Flex. Portal Aeroin, [S. I.], 13 mai. 2020b. Disponível em: https://www.aeroin.net/azul-conclui-amanha-a-compra-da-twoflex/. Acesso em: 21 dez. 2020.

FERREIRA, J. Um breve histórico da aviação comercial brasileira. In: CONGRESSO BRASILEIRO DE HISTÓRIA ECONÔMICA, 12.; CONFERÊNCIA INTERNACIONAL DE HISTÓRIA DE EMPRESAS, 13., 2017, Niterói. Anais [...] Niterói: Associação Brasileira de Pesquisadores em História Econômica, 2017. p. 1-27. Disponível em: http://www.abphe.org.br/uploads/ABPHE\%202017/16\%20Um\%20breve\%20hist\%C3\%B3rico\%20da\%20avia\%C3\%A7\%C3\%A30\%20c omercial\%20brasileira.pdf. Acesso em: 15 dez. 2020.

FERREIRA, M. M. (coord.). A República na Velha Província. Rio de Janeiro: Rio Fundo, 1989.

FREIRE, Q. Rio volta a ter voos para Campos e Macaé pela Azul. Diário do Rio, Rio de Janeiro, 20 nov. 2020. Disponível em: https://diariodorio.com/rio-volta-a-ter-voos-para-campos-e-macae-pela-azul/. Acesso em: 28 dez. 2020.

GAIER, R. RJ reduz ICMS de combustível para aumentar número de voos. G1, Rio de Janeiro, 13 nov. 2019. Disponível em: https://g1.globo.com/rj/rio-de-janeiro/noticia/2019/11/13/rj-reduz-icms-de-combustivel-para-aumentar-oferta-de-voos.ghtml. Acesso em: 30 dez. 2020.

GARGIULO, F. R. Indústria de Construção Aeronáutica, o caso da Embraer: história e avaliação. 2008. Dissertação (Mestrado em Finanças e Economia Empresarial) - Escola de Pós-Graduação em Economia, Fundação Getúlio Vargas, Rio de Janeiro, 2008. Disponível em: https://bibliotecadigital.fgv.br/dspace/bitstream/handle/10438/2157/055204018-

Flavio_Riva.pdf?sequence=1\&isAllowed=y. Acesso em: 15 dez. 2020.

GATOEIRO, F. Cabo Frio (RJ) inaugura aeroporto internacional. Portal Panrotas, São Paulo, 26 set. 2007. Disponível em: https://www.panrotas.com.br/noticia-turismo/aviacao/2007/09/cabo-frio-rj-inaugura-aeroporto-internacional-_32500.html. Acesso em: 24 dez. 2020.

GOMES, S.; LACERDA, S.; BASTOS, V.; CASTRO, M. Aviação Regional Brasileira (Modal Aéreo IV). Informe Infra-Estrutura, Rio de Janeiro, n. 50, 2002. Disponível em:https://www.bndes.gov.br/SiteBNDES/export/sites/default/bndes_pt/Galerias/Arquivos/conhecimento/infra/Inf02-50.pdf. Acesso em: 21 dez. 2020.

HARVEY, D. Seventeen contradictions and the end of capitalism. New York: Oxford University Press, 2014 
IBGE - Instituto Brasileiro de Geografia e Estatística. Coordenação de Geografia. Nota técnica 01/2020. Acompanha a divulgação de informações socioeconômicas e demográficas com o objetivo de assistir ao enfrentamento da COVID-19. Rio de Janeiro: IBGE, 7 mai. 2020a. Disponível em:

https://agenciadenoticias.ibge.gov.br/media/com_mediaibge/arquivos/9329c127e50825491a23f679e6469a61.pdf. Acesso em: 13 dez. 2020.

IBGE - Instituto Brasileiro de Geografia e Estatística. Regiões de Influência das Cidades: 2018. Rio de Janeiro: IBGE, 2020b.

IBGE - Instituto Brasileiro de Geografia e Estatística. Arranjos populacionais e concentrações urbanas do Brasil. 2. ed. Rio de Janeiro: IBGE, 2016.

IBGE - Instituto Brasileiro de Geografia e Estatística. Ligações aéreas: 2010. Rio de Janeiro: IBGE, 2013.

IBGE - Instituto Brasileiro de Geografia e Estatística. Regiões de Influência das Cidades: 2007. Rio de Janeiro: IBGE, 2008.

IBGE - Instituto Brasileiro de Geografia e Estatística. Regiões de Influência das Cidades: 1993. Rio de Janeiro: IBGE, 2000.

INAUGURADAS as novas instalações do Aeroporto do Galeão. A Noite, Rio de Janeiro, ano 1952, n. 14.009, p. 11, 1 fev. 1952. Disponível em: http://memoria.bn.br/docreader/DocReader.aspx?bib=348970_05\&pagfis=10998. Acesso em: 20 dez. 2020.

INCENTIVOS oficiais à aviação regional existiram entre 1975 e 1999. Em Discussão, Brasília, DF, nov. 2010. Disponível em: https://www.senado.gov.br/noticias/Jornal/emdiscussao/revista-em-discussao-ediao-novembro-2010/materias/incentivos-oficiaisa-aviaao-regional-existiram-entre-1975-e-1999.aspx. Acesso em: 14 dez. 2020.

LEURQUIN, P.; AVELAR, M. Os desafios jurídicos e econômicos da aviação regional no Brasil. Revista Brasileira de Políticas Públicas. Brasília, DF, v. 6, n. 2, p. 204-221, out. 2016. Disponível em: ttps://www.publicacoesacademicas.uniceub.br/RBPP/article/view/3979. Acesso em: 26 dez. 2020.

LOPES, J. Capital privado em aeroportos: a experiência do Rio de Janeiro, 23 abr. 2009. 16 slides. Disponível em: https://www.fiesp.com.br/arquivo-download/?id=2113. Acesso em: 26 dez. 2020.

LUNA, M.; LUNA, P.; FRIES, C.; MOTTA, K. Planejamento de Logística e Transporte no Brasil: uma Análise dos Planos Nacional e Estaduais. In: CONGRESSO DE PESQUISA E ENSINO EM TRANSPORTES, 25., 2011, Belo Horizonte. Anais [...]. Belo Horizonte: Associação Nacional de Pesquisa e Ensino em Transportes, 2011. Disponível em: http://nures.ufsc.br/wpcontent/uploads/2010/10/PLANEJAMENTO-DE-LOG\%C3\%8DSTICA-E-TRANSPORTE-NO-BRASIL-UMA-AN\%C3\%81LISE.pdf. Acesso em: 15 dez. 2020.

MARAFON, G. J.; RIBEIRO, M. A.; CORRÊA, R. S.; VASCONCELOS, V. N. Geografia do Estado do Rio de Janeiro: da Compreensão do Passado aos Desafios do Presente. Rio de Janeiro: Gramma, 2011.

MARTINS, C. Gol inicia as vendas para a apelidada "Ponte Aérea da Barra". Portal Aeroin, [S. I.], 06 out. 2019 [2019a]. Disponível em: https://www.aeroin.net/twoflex-gol-iniciam-venda-passagens-ponte-aerea-barra/. Acesso em: 28 dez. 2020.

MARTINS, C. Aeroportos regionais vão receber mais de R\$ 200 milhões para melhoria da infraestrutura. Portal Aeroin, [S. I.], 20 dez. 2017. Disponível em: https://www.aeroin.net/aeroportos-regionais-vao-receber-mais-de-r-200-milhoes-para-melhoria-dainfraestrutura/. Acesso em: $30 \mathrm{dez} .2020$.

MARTINS, M. Aeroporto de Macaé (RJ) reabre após obras de R\$ 90 milhões. Portal Panrotas, São Paulo, 11 mar. 2019 [2019b]. Disponível em: https://www.panrotas.com.br/aviacao/aeroportos/2019/03/aeroporto-de-macae-rj-reabre-apos-obras-de-r-90milhoes_162857.html. Acesso em: 15 dez. 2020.

MATTOS, B. História da Embraer. Portal Aeita, São José dos Campos, [200-]. Disponível em: http://www.aeitaonline.com.br/wiki/images/9/92/HistoriaEmbraer.PDF. Acesso em: 20 dez. 2020.

MENEZES, P. Azul retoma operações em Cabo Frio (RJ). Mercado \& Eventos: Portal Brasileiro de Turismo, São Paulo, 14 dez. 2020. Disponível em: https://www.mercadoeeventos.com.br/noticias/aviacao/azul-retoma-operacoes-em-cabo-frio-rj/. Acesso em: 28 dez. 2020.

NIEMEYER, F. Começam obras de ampliação do Aeroporto de Cabo Frio. Portal Panrotas, São Paulo, 02 jun. 2010. Disponível em: https://www.panrotas.com.br/service-news/reader/reader.asp?cod_not=58415. Acesso em: 24 dez. 2020.

NOVAES, A.; SOUZA, A. Nas asas da Geografia com a aviação regional. GeoUERJ, Rio de Janeiro, n. 34, p. 1-20, jan./jun. 2019. Disponível em: https://www.e-publicacoes.uerj.br/index.php/geouerj/article/view/32772/29747. Acesso em: 25 dez 2020. 
PESSOA, L. História da Aviação Comercial Brasileira. São Paulo: Rios, 1989.

PRONTA Referência. O Guia Panrotas, São Paulo, ano 26, n. 309, dez. 1996. Pronta Referência, p. B-218. Disponível em: https://issuu.com/panrotas/docs/1998-12-309. Acesso em: 19 dez. 2020.

RAFFESTIN, C. Por uma geografia do poder. São Paulo: Ática, 1993.

RIBEIRO, M. A. Considerações sobre o Espaço Fluminense: Estrutura e Transformações. In: MARAFON, G.; RIBEIRO, M. (org.). Estudos de Geografia Fluminense. [S. I.]: Infobook, p. 13-26, 2002.

RIBEIRO, M. A. Abordagens Analíticas das Redes Geográficas. Boletim Goiano de Geografia, Goiânia, v. 20, n. 1-2, p. 77-105, jan./dez. 2000.

RIBEIRO, M. A.; O'NEILL, M. M. Contrastes entre a metrópole e o interior fluminense a partir do urbano e do rural. In: FERNANDES, U. S.; RIBEIRO, M. A.; ABRANCHES JUNIOR, N. (org.). Velhos Saberes, Novas Abordagens: a Geografia à Luz da Contemporaneidade. Rio de Janeiro: Gramma, p. 1-15, 2015.

RIO DE JANEIRO (Estado). Lei Complementar no 184, de 27 de Dezembro de 2018. Dispõe sobre a região metropolitana do rio de janeiro, sua composição, organização e gestão, define as funções públicas e serviços de interesse comum, cria a autoridade executiva da região metropolitana do rio de janeiro e dá outras providências. Rio de Janeiro, RJ: Governo do Estado, 2018. Disponível em: https://www.jusbrasil.com.br/topicos/213454669/lc-n-184-de-27-de-dezembro-de-2018-do-rio-de-janeiro. Acesso em: 18 dez. 2020.

RIO DE JANEIRO (Estado). Secretaria de Estado de Transportes, Coordenadoria de Transporte Aeroviário. PAERJ: Plano Aeroviário do Estado do Rio de Janeiro - 2017. Rio de Janeiro, RJ: Governo do Estado, 2017. Disponível em:

http://www.rj.gov.br/Uploads/Noticias/10937PAERJ\%20SETRANS\%202017.pdf. Acesso em: 15 dez. 2020.

ROSS, J. L. S. Relevo brasileiro: uma nova proposta de classificação. Revista do Departamento de Geografia da USP, São Paulo, v. 4, p. 25-39, 1985.

SANTOS, M. A natureza do espaço. 4. ed. São Paulo: Edusp, 2017 [1996].

SASSEN, S. The global-city: New York, London, Tokyo. 2. ed. Princeton: Princeton University Press, 2001 [1991].

SOUZA, M. L. Os conceitos fundamentais da pesquisa sócio-espacial. Rio de Janeiro: Bertrand Brasil, 2013.

TEIXEIRA, T. Pouso do primeiro voo ligando Macaé ao Rio de Janeiro marca retorno da Azul Linhas Aéreas ao município. Portal Clique Diário, Macaé, 9 dez. 2019. Disponível em: https://cliquediario.com.br/politica/pouso-do-primeiro-voo-ligando-macae-ao-rio-dejaneiro-marca-retorno-da-azul-linhas-aereas-ao-municipio. Acesso em: 29 dez. 2020.

ÚNICA companhia aérea que atende Macaé, RJ, anuncia fim das operações. G1, Região dos Lagos, 15 jul. 2015. Disponível em: http://g1.globo.com/rj/regiao-dos-lagos/noticia/2015/07/unica-companhia-aerea-que-atende-macae-rj-anuncia-fim-dasoperacoes.html. Acesso em: 15 dez. 2020.

VIANA, P. Azul renomeia a Two Flex como "Azul Conecta". Portal Aeroflap, [S. I.], 2020. Disponível em: https://www.aeroflap.com.br/azul-renomeia-a-twoflex-como-azul-conecta/.Acesso em: 15 dez. 2020.

VIEIRA, B. Acordo de céus abertos entre EUA e União Europeia: uma visão geral. Journal of Transport Literature, Manaus, v. 6, n. 1, p. 200-220, jan. 2012. Disponível em: https://www.scielo.br/pdf/jtl/v6n1/v6n1a13.pdf. Acesso em: 15 dez. 2020.

VIEIRA, R. Azul Conecta voará a Canela, Búzios, Ubatuba, Jeri e mais 5 destinos. Portal Panrotas, São Paulo, 17 nov. 2020. Disponível em: https://www.panrotas.com.br/aviacao/novas-rotas/2020/11/azul-conecta-voara-a-canela-buzios-ubatuba-jeri-e-mais-5destinos_178040.html. Acesso em: $28 \mathrm{dez} .2020$. 